\title{
SOCIOS PERO NO PARIENTES. LOS LÍMITES DE LA PROMOCIÓN SOCIAL DE LOS COMERCIANTES EXTRANJEROS EN LA CASTILLA MODERNA ${ }^{1}$
}

\author{
Pedro Miralles Martínez \\ Universidad de Murcia \\ Sebastián Molina PuChe \\ École des Hautes Études en Sciences Sociales-CNRS París
}

RESUMEN: Con el análisis de la familia Ferro Verdín, mercaderes murcianos de origen genovés, pretendemos mostrar que el dinero, en la Castilla moderna, era un elemento necesario, pero no suficiente, para ascender socialmente. Intentamos así revisar la poca importancia que, en los procesos de promoción social, algunas investigaciones recientes han otorgado al factor honorífico, relegado a un plano secundario frente al factor económico. Se estudian cinco generaciones de esta familia, en el transcurso de las cuales los Ferro, para ser reconocidos como miembros de la elite local murciana, tuvieron que abandonar la actividad comercial y adoptar todas las señas de identidad de dicho grupo social. La elite local hacía negocios con ellos, pero se mostraba remisa a emparentar con una familia de mercaderes. No sería hasta la cuarta generación cuando consiguen enlazar con la oligarquía linajuda: hasta ese momento sólo logran casar con miembros de los estratos intermedios de la oligarquía o de elites foráneas. No cabe duda que la posesión de riqueza facilitó, vía obtención de honras y oficios prestigiosos, el ascenso social de numerosas familias. Pero ni siquiera en el caso de una familia tan rica y bien situada en la administración regia y la Iglesia como la que nos ocupa, la posesión de estos capitales suponía una fácil y rápida integración en una elite tan "tradicional» como era la de la ciudad de Murcia.

\footnotetext{
${ }^{1}$ El presente trabajo forma parte del proyecto de investigación «Sociedad, familias y grupos sociales. Redes y estrategias de reproducción socio-cultural en Castilla durante el Antiguo Régimen (siglos XV-XIX)», referencia: HUM2006-09559, del que es Investigador Principal Francisco Chacón, y ha sido financiado por el Ministerio de Educación y Ciencia (Secretaría de Estado de Universidades e Investigación). Las fuentes utilizadas han sido de tipo fiscal —libros del Contraste de la seda-, actas capitulares, documentos notariales, cartas reales, fuentes parroquiales y legajos con contenido diverso.
} 


\title{
PALABRAS CLAVE: Movilidad social. comercio. mercaderes extranjeros. Castilla. Edad Moderna.
}

\begin{abstract}
With the analysis of the family Ferro Verdin, merchants murcians of Genoese origin, we try to show that the money, in the modern Castile, was a necessary, but not sufficient element, to ascend socially. We try to check this way little importance that, in the processes of social promotion, some recent investigations have granted to the honorific factor relegated to a secondary plane, opposite to the economic factor. There are studied five generations of this family, in the course of which the Ferro, to be recognized as members of the murcian local elite, had to leave the commercial activity and adopt all the signs of identity of the above mentioned social group. The local elite was doing business with them, but it was proving to be remiss to relating with a merchants' family. It would not be up to the fourth generation when they manage to connect with the highborn oligarchy: up to this moment only they manage to marry members of the intermediate strata of the oligarchy or of foreign elites. Doubt does not fit that the possession of richness facilitated, route obtaining of honors and prestigious offices, the social ascent of numerous families. But not at least in case of a family so rich and placed well in the royal administration and the Church like that she occupies us, the possession of these capitals supposed an easy and rapid integration in an elite as "traditional» as it was that of the city of Murcia.
\end{abstract}

KEY WORDS: Social mobility. trade. foreign merchants. Castile. Early Modern Age.

\section{Dinero y ASCENSO SOCIAL EN LA CASTILlA MODERNA}

«...el dinero del mundo es grand revolvedor señor façe del siervo, del señor servidor...2».

No cabe duda que el dinero, en las teóricamente herméticas sociedades estamentales del Antiguo Régimen, fue uno de los principales factores de movilidad social. Tras varios decenios de estudios en los que se han sucedido los trabajos sobre los medios y las vías de la promoción social en la Castilla moder$\mathrm{na}^{3}$, ha quedado perfectamente demostrado que, sobre todo a partir de la se-

2 Juan RuIZ, arcipreste de Hita: Libro del buen amor (ed. Madrid, 1999, p. 96, capítulo XXXVII: «Exienplo de la propiedat quel dinero ha»).

3 Sobre todo desde que, como ha señalado el profesor Chacón Jiménez, en los años setenta del pasado siglo se asistiera a una renovación en los métodos y objetivos de trabajo en la historiografía española (CHACÓN JIMÉNEZ, Francisco: «Población, familia y relaciones de poder. Notas y reflexiones sobre la organización social hispánica: circa siglo XV-circa siglo XVII», en RODRÍGUEZ CANCHO, Miguel (coord.): Historia y perspectivas de investigación. Estudios en memoria del profesor Ángel Rodríguez Sánchez, Mérida, 2002, pp. 85-95), dando paso a lo que ha sido denominado como «nueva historia social». A este respecto, véase HERNÁNDEZ FRANCO, Juan: «El reencuentro entre historia social e historia política en torno a las familias de poder. Notas y seguimiento a través de la historiografía sobre la Castilla Moderna», en Stvdia Histórica. Historia Moderna (Salamanca) 18 (1998), pp. 179-199. 
gunda mitad del siglo $\mathrm{XVI}^{4}$ (aunque las palabras de Juan Ruiz, arcipreste de Hita, con las que abrimos este artículo, demuestran que se trata de un proceso iniciado mucho antes), el dinero parece ser el principal vehículo para lograr el ascenso social. De hecho, y como muy bien ha señalado Jaime Contreras, «la realidad social cotidiana se encontraba más dinamizada por las presiones de la riqueza que por la resistencia del honor ${ }^{5}$ ».

Evidentemente, con estos trabajos se ha superado la imagen ideal de la práctica impermeabilidad de los estamentos que aparece en la tratadística de la época ${ }^{6}$. Ahora bien, de esa imagen de quietismo se ha pasado a otra, igualmente idealizada, en la cual parece que la movilidad social era continua y nada excepcional, y en la cual la posesión de dinero era un requisito suficiente para ascender en la sociedad. El nacimiento, la cuna, han pasado a tener muy poco valor en muchos de esos análisis históricos. Volviendo sobre la cita del profesor Contreras, se podría decir que, al enfatizar las presiones de la riqueza, se ha terminado olvidando la resistencia del honor.

La causa de esta «nueva visión» de la sociedad castellana del Antiguo Régimen, ofrecida por parte de la reciente historiografía española, podemos hallarla en el hecho de que no han sido pocos los autores que se han dejado deslumbrar por aquellos ejemplos (que, evidentemente, existen en cierto número) en los que un individuo, gracias sobre todo a su dinero, protagoniza un vertiginoso y llamativo caso de promoción social. La profusión de estudios basados en estos ejemplos (unos trabajos que, en algunas ocasiones, acaban siendo una especie de hagiografías laudatorias), raramente contrapuestos a casos opuestos $^{7}$ que puedan dar una visión contrastada de la sociedad, y en muy po-

4 No vamos a detenernos en un proceso de sobra conocido como es el de la influencia, en la sociedad castellana (pero no sólo en ella, como lo demostraron, en su día, L. Stone para el caso inglés y R. Mousnier para Francia: STONE, Lawrence: La crisis de la aristocracia 1558-1641, Madrid, 1985; MOUSNIER, Roland: La venalité des offices sous Henri IV et Louis XIII, París, 1971), de la venta de cargos y honores por parte de la Corona para intentar paliar el desequilibrio existente entre los parcos ingresos obtenidos por un sistema fiscal todavía rudimentario y unas necesidades monetarias cada vez más elevadas. A modo de ejemplo, véase el reciente trabajo de FAYA DíAZ, Ma Ángeles: "Gobierno municipal y venta de oficios en la Asturias de los siglos XVI y XVII», en Hispania (Madrid) 213 (2003), pp. 75-136.

5 CONTRERAS, Jaime: «Linaje y cambio social: la manipulación de la memoria», en Historia Social (Valencia) 21 (1995), pp. 96-118.

6 A este respecto véase, por ejemplo, GuILlÉn BERRENDERO, José Antonio: «La tratadística nobiliaria como espejo de nobles: el ejemplo de Juan Benito Guardiola y su tratado de nobleza de 1591», en Brocar (Logroño) 26 (2002), pp. 81-106.

7 De hecho, son muy pocas, en comparación, las obras que han tratado el descenso social de una familia. Como ejemplos honrosos, podemos citar a HERNÁNDEZ FRANCO, Juan: «Trayectoria social de una familia conversa: los Santesteva-Lara. Del empinamiento a la condena», en MESTRE SANCHÍs, Antonio y GiménEZ LÓpeZ, Enrique (eds.): Disidencias y exilios en la España Moderna, Alicante, 1997, pp. 179-192, y HAMON, P.: «La chute de la maison de Thou: la fin d'une dynastie robine», en Revue d'Historie Moderne et Contemporaine (Paris), 46-1 (1999), pp. 53-84. 
cos casos acompañados de una comprobación o cálculo (y no sólo en términos cuantitativos) de hasta qué punto son comunes estos procesos en el contexto donde se producen, ha provocado la generalización de esta «nueva visión» de la sociedad castellana moderna a la que estamos haciendo referencia.

Pero tal vez lo más preocupante es que estos estudios (y principalmente aquellos centrados en el siglo del Barroco) han terminado por crear una especie de modelo según el cual todo individuo enriquecido, con independencia de su origen, puede subir en la escala social tanto como le plazca - - , al menos, tanto como le alcance el dinerofacilitan, cuando no alientan, el ascenso social basado únicamente en la prestación de servicios pecuniarios.

En un trabajo cuyo objeto de estudio son los comerciantes, no es nuestra intención poner en tela de juicio la veracidad de dicho modelo. Hacerlo sería tanto como pretender negar la existencia de la movilidad social en Castilla y la paulatina valorización del factor económico en el mismo utilizando, justamente, uno de los sectores de la sociedad que más ejemplos de ello ha dado a la historiografía. No obstante, sí que vamos a intentar matizarlo y, sobre todo, limitar la capacidad transgresiva que se le ha otorgado al dinero, es decir, el «poder» del peculio en los procesos de movilidad social.

Es posible que, como han señalado algunos autores ${ }^{9}$, en lo relativo a la organización social, la Edad Moderna no sea más que un período de transición entre la Edad Media _en la que existe un claro predominio nobiliario_- y la Contemporánea —en la cual la hegemonía está en manos de la burguesía y su ética-. Por esa misma razón, no podemos minusvalorar el valor que comienza a tener el mérito personal y el dinero ${ }^{10}$, pero tampoco podemos enfatizarlo hasta el punto de olvidar la permanencia de los valores nobiliarios. Don dinero es un caballero poderoso - parafraseando a Quevedo-, consigue abrir muchas puertas y permite obtener ciertos «bienes ${ }^{11}$ «que otorgan honor y capacidad de dominio, pero no puede acabar con toda la resistencia que, a lo largo de los siglos XVI al XVIII, opone el honor. De hecho, y como vamos a intentar demostrar a continuación por medio de una de las familias de comerciantes más

8 Véase, por ejemplo, Gelabert, Juan Eloy: La bolsa del Rey. Rey, reino y fisco en Castilla (1598-1648), Barcelona, 1997.

9 CASEY, James: Historia de la familia, Madrid, 1990.

10 Molina Puche, Sebastián: «La diferenciación social en el siglo XVII. Las elites locales del corregimiento de Chinchilla-Villena», en Historia Social (Valencia) 58 (2007), pp. 3-22.

${ }_{11}$ Nos referimos, como no podía ser de otra manera, a oficios de poder (como los denominaba Francisco Tomás Y VALIENTE: «Ventas de oficios públicos en Castilla durante los siglos XVII y XVIII», en TOMÁs y VALIENTE, Francisco: Gobierno e instituciones en la España del Antiguo Régimen, Madrid, 1999, pp. 151-177), privilegios de hidalguía, hábitos de Ordenes Militares, señoríos, títulos nobiliarios, e incluso Grandezas de España (son muchas las obras de referencia sobre este particular, no obstante, una de las primeras en tratarlo es, también, una de las mejores síntesis realizadas sobre el tema: DomínGUEZ ORTIZ, Antonio: La sociedad española en el siglo XVII. El estamento nobiliario, Granada, 1992). 
ricas de la Murcia de los siglos XVII y XVIII, es incapaz de adquirir uno de los principales factores de distinción: el reconocimiento social, la aceptación por parte del grupo social al que se aspira a formar parte.

\section{LOS GENOVESES EN EL REINO DE MURCIA: PAPEL ECONÓMICO Y COMPOR- TAMIENTO SOCIAL}

«...los tratantes de Génova, que traen las conciencias en faltriqueras descosidas, de donde se les pierde y ninguno la tiene... ${ }^{12 » .}$

La presencia genovesa en el Reino de Murcia se remonta al momento de la reconquista cristiana ${ }^{13}$ y se encuentra vinculada, principalmente, al comercio de la lana. No obstante, y aunque hay constancia de sus actividades en esas fechas tan tempranas, no será hasta finales del siglo XV cuando la importancia de la colonia genovesa en la zona se haga más notoria, pues es a partir de este momento cuando se constituyen en una poderosa minoría ${ }^{14}$ que logra vertebrar el comercio murciano ${ }^{15}$, protagonizando la incorporación de Murcia a las redes del comercio internacional ${ }^{16}$ monopolizando, especialmente, el gran comercio

12 Alemán, Mateo: Guzmán de Alfarache, edición de José Ma Micó, Madrid, 1997, I, p. 410.

13 Molina Molina, Ángel Luis: "Mercaderes genoveses en Murcia durante la época de los Reyes Católicos», en La sociedad murciana en el tránsito de la Edad Media a la Moderna, Murcia, 1996, pp. 23-29. En este sentido, el caso de Murcia es semejante al de otros territorios castellanos, es decir, con la conquista cristiana llegan también las primeras colonias comerciales genovesas: véase, a este respecto, los trabajos recogidos en AA VV: Presencia italiana en Andalucía. Siglos XIV-XVII, Sevilla, 1989; y Villar GarcíA, Begoña y PeZzi CristóBAL, Pilar (eds.): Los extranjeros en la España Moderna. Actas del I Coloquio Internacional. Málaga, 2003, 2 vols.

14 Sobre la expansión comercial genovesa por el Mediterráneo, véase JEHEL, Georges: Les Génois en Méditerranée occidentale: fin XIe-début XIVème siècle: ébauche d'une stratégie pour un empire, Amiens, 1993; y los trabajos recogidos en la ya citada La presencia italiana..., ob. cit.

15 Torres Fontes, Juan: "Genoveses en Murcia (siglo XV)», en Miscelánea Medieval Murciana (Murcia) 2 (1976), pp. 71-168; MENJOT, Denis y CECHI, Elena: «Murcie dans le grand commerce international a l'orée du XVe siècle d'après les archives Datini. Notes et documents», en Miscelánea Medieval Murciana (Murcia) 15 (1990), pp. 121-137; MARTínez MARTíNEZ, María: La industria del vestido en Murcia, siglos XIII-XIV, Murcia, 1987, pp. 119, 154, 253-254; Montojo Montojo, Vicente: «Mercaderes y actividad comercial a través del Puerto de Cartagena en los reinados de los Reyes Católicos y Carlos V (1474-1555)», en Miscelánea Medieval Murciana (Murcia) 18 (1994), pp. 109-140.

16 Sobre las mismas, véanse, por ejemplo, los trabajos recogidos en CURTO, Diogo y MOLHO, Anthony (ed.): Commercial Networks in the Early Modern World, Florencia, 2002; y el monográfico que a las «reseaux marchands» dedica la revista Annales. Histoire, Sciences sociales (Paris) en su número 58-3 (mayo-junio 2003), en el cual podemos destacar los artículos de TrivelLATO, Francesca: «Juifs de Livourne, Italiens de Lisbonne, hindous de Goa. Reseaux marchands et echanges interculturels a 1'epoque moderne», pp. 581-604; y el trabajo conjunto de los ya citados MoLHO, Anthony y CURTO, Diogo: «Les réseaux marchands à l'époque moderne», pp. 569-580. 
de materias primas textiles ${ }^{17}$.

Dos van a ser las razones que explican el aumento de la influencia genovesa en la economía murciana. La primera es la expulsión de los judíos, un hecho que les va a posibilitar la realización, junto a sus tradicionales actividades comerciales, de otras funciones que anteriormente ejercía la comunidad hebrea: prestamistas, banqueros, administradores, arrendadores o recaudadores de impuestos y rentas reales, señoriales, eclesiásticas y municipales... Es decir, una serie de actividades que les van a facilitar entrar en contacto con la oligarquía local (el concejo va a precisar de sus servicios financieros), la corona y la sociedad ciudadana.

La segunda razón es que, a finales del siglo XV, los ligures comienzan a desligarse de su metrópoli: si hasta ese momento han actuado casi exclusivamente como meros factores o agentes de las grandes compañías comerciales genovesas, ahora empiezan a mostrar interés por asentarse definitivamente en el territorio. Evidentemente, se trata de una «desvinculación» relativa, pues no va a suponer, en modo alguno, una ruptura definitiva con sus ciudades de origen y, mucho menos, con la parentela y socios comerciales que allí pudieran tener: la diferencia con etapas anteriores se reduce a que el mercader no pretende volver a Génova tras la realización de las transacciones comerciales ${ }^{18}$. Este interés por echar raíces en el territorio donde se está comerciando no es, en modo alguno, una característica privativa de los ligures asentados en territorio murciano, pues en otros puntos de la península ${ }^{19}$ (y también fuera de ella ${ }^{20}$ )

${ }_{17}$ Desde la Baja Edad Media, Murcia entra en el sistema económico internacional cumpliendo una función claramente periférica (esto es, se convierte en abastecedora de materias primas y consumidora de productos manufacturados, véase LEMEUNIER, Guy: «Las implicaciones de la condición periférica en el Reino de Murcia (1480-1650)», en Áreas. Revista de Ciencias Sociales (Murcia) 5 (1986), pp. 88-97), que se hará mucho más evidente en etapas posteriores: véase WALLERSTEIN, Immanuel: «Subdesarrollo y fase B, efectos del estancamiento del siglo XVII en el centro y la periferia de la economía-mundo europea», en En Teoría (Madrid) 3 (1979), p. 52, y también FERNÁNDEZ DE PINEDO, Emiliano: «Comercio colonial y semiperiferización de la monarquía hispana en la segunda mitad del siglo XVII», en Áreas. Revista de Ciencias Sociales (Murcia) 5 (1986), pp. 125-138. En este sentido, Génova se convierte en uno de los principales socios comerciales de la región: véase MENJOT, Denis: «Estructuras sociales y modelos de desarrollo en los países mediterráneos durante la Edad Media, el ejemplo del mercado murciano (12661492)», en Áreas. Revista de Ciencias Sociales (Murcia) 5 (1986), pp. 50-63.

${ }_{18}$ PÉrez PicAzo, Ma Teresa y Lemeunier, Guy: El proceso de modernización de la Región Murciana (siglos XVI-XIX), Murcia, 1984, p. 68.

${ }_{19}$ Entre los numerosos trabajos sobre el comercio genovés en el ámbito español y europeo destacamos los recogidos en BeLVEDERI, Raffaele (ed.): I, II y III Congresso Internazionale di studi storici. Rapporti Genova-Mediterraneo-Atlantico nell'Età Moderna, Génova, 1990; FranCH BeNAVENT, Ricardo: «Dinastías comerciales genovesas en la Valencia del siglo XVIII, los Causa, Batifora y Ferraro», en La documentación notarial y la Historia. Actas del II Coloquio de Metodología Histórica Aplicada, Santiago de Compostela, 1984, pp. 117-13, vol. II, pp. 295-31; GRENDI, E: La repubblica aristocratica dei genovesi, Politica, carità e commercio fra Cinque e Seicento, Bolonia, 1987; Melis, Federigo: Mercaderes italianos en España (siglos XIV-XVI), Sevilla, 1976; MONTEMAYOR, Julián: "Quelques affaires génoises à Tolède à la fin du XVI ${ }^{e}$ siècle», en La documentación notarial..., ob. cit., 
se están produciendo casos similares ${ }^{21}$. No obstante, en esta zona se origina un hecho significativo que no resulta demasiado habitual, no al menos en fechas tan tempranas ${ }^{22}$ : los genoveses no se contentan con asentarse en el territorio, sino que se esfuerzan por integrarse en la sociedad murciana, para lo cual siguen una estrategia basada en la adquisición de bienes inmuebles y el entroncamiento matrimonial con, principalmente, mercaderes locales ${ }^{23}$.

Una estrategia de «enraizamiento» e integración ${ }^{24}$ que también seguirán las

vol. II, pp. 287-293; NAVARRO ESPINACH, Germán: «Los genoveses y el negocio de la seda en Valencia (1457-1512)», en Anuario de Estudios Medievales (Madrid) 24 (1994), pp. 201-224; PIKE, Ruth: Aristócratas y comerciantes. La sociedad sevillana en el siglo XVI, Barcelona, 1978; PUIZ, A. M: «Marchands genevois du monde méditerranéen (vers. 1600-1630)», en Historie economique du monde mediterránen, 1450-1600 (Mélanges en l'honneur de Fernand Braudel), Toulouse, 1973, pp. 459-470; VILlar García, Begoña y PeZzi CrIstóBAL, Pilar (eds.): ob. cit.; FRANCH BENAVENT, Ricardo: «La inmigración italiana en la España moderna», en GonZÁlez Lopo, Domingo L. y EIRAS Roel, Antonio (coords.): La inmigración en España, Santiago de Compostela, 2004, pp. 103-145; Álvarez NogAL, Carlos: «Las compañías bancarias genovesas en Madrid a comienzos del siglo XVII», en Hispania (Madrid) 219 (2005), pp. 67-90; SANZ AYÁN, Carmen: «Presencia y fortuna de los hombres de negocios genoveses durante la crisis hispana de 1640», en Hispania (Madrid) 219, (2005), pp. 91-114.

${ }^{20}$ Sobre este particular, véanse los trabajos recogidos en BotTIN, Jacques y CALABI, Donatella (ed.): Les étrangers dans la ville. Minorités et espace urbain du bas Moyen Age à lépoque moderne, Paris, 1999.

${ }^{21}$ Igual, David y Navarro, G: «Los genoveses en España en el tránsito del siglo XV al XVI», en Historia. Instituciones. Documentos (Sevilla) 24 (1997), pp. 261-332.

22 Como ha señalado Franch Benavent, a lo largo del siglo XV los asentamientos genoveses en los centros mercantiles de la Península Ibérica tuvieron, principalmente, un carácter temporal y transitorio (FRANCH BENAVENT, Ricardo: «Los genoveses en la España Moderna: finanzas, comercio y actividad laboral de los protagonistas de un intenso flujo migratorio», en GALLIARI, Luciano (ed.): Genova. Una porta del Mediterraneo, Génova, 2005, pp. 643-683), algo que, evidentemente, cambiará en fechas posteriores.

${ }^{23}$ Una de las razones que explican el interés de los comerciantes genoveses por avecindarse en ciudades como Cartagena y Murcia es que, adquiriendo la condición de vecinos, pueden gozar de los privilegios y franquezas inherentes a la misma. En Cartagena, el avecindamiento de genoveses acabaría creando recelos y oposiciones por parte de los mercaderes naturales: véase MONTOJO MONTOJO, Vicente: El Siglo de Oro de Cartagena: 1480-1640, evolución económica y social de una ciudad portuaria del sureste español y su comarca, Murcia, 1993, pp. 253-254. También de este autor: Cartagena en la época de Carlos V. Crecimiento demográfico, transformaciones económicas y conflictividad social, Murcia, 1987, p. 127. Algo que también ocurrió en otras plazas comerciales, como, por ejemplo, Valencia: SALVADOR ESTEBAN, Emilia: «Mercaderes extranjeros en la Valencia de los siglos XVI y XVII», en ENCISO RECIO, Luis Miguel (coord.): La burguesía española en la Edad Moderna, II, Valladolid, 1996, pp. 1148-1149.

${ }^{24}$ Como más tarde veremos, su integración llega a ser tal que, al igual que los grupos de poder local autóctonos, crean vínculos y mayorazgos, acceden a cargos políticos en el concejo (jurado, regidor, alcalde); entran al servicio militar del rey (capitán de la milicia, gentilhombre de artillería); se insertan en la burocracia inquisitorial (familiar, nuncio, receptor, «intérprete de lenguas»); ocupan puestos en la jerarquía eclesiástica (desde síndico de algún convento o racionero hasta abadesa u obispo); gestionan la recaudación fiscal... Gracias a estrategias matrimoniales ventajosas, a su riqueza y a la creación de mayorazgos consiguieron acceder a la hidalguía (incluso algunos, como los Dardalla, llegarán a poseer señoríos: CHACón JimÉnEZ, Francisco y MONTOJO MONTOJO, Vicente: «Señoríos y poder monárquico en Murcia (siglos XVI-XVII)», en SARASA SánCHEZ, 
nuevas oleadas de genoveses que, desde comienzos del siglo XVI, llegan al Reino de Murcia ${ }^{25}$, y sobre todo a la ciudad portuaria de Cartagena ${ }^{26}$, atraídos por el ya tradicional comercio de materias primas para la manufactura textil (lana, sosa y barrilla), pero también por el del alumbre ${ }^{27}$ de las minas de Mazarrón ${ }^{28}$ y el incipiente comercio con América ${ }^{29}$. La vinculación de los comerciantes genoveses a la sociedad cartagenera va a ser total, es más, no sólo no van a dar muestra alguna de intentar abandonar la ciudad ${ }^{30}$ sino que, además, van a facilitar la llegada de nuevos parientes suyos a la zona ${ }^{31}$. Unos parientes que, cada

Esteban y Serrano Martín, Eliseo (ed.): Señorío feudalismo en la Península Ibérica, Tomo II, Zaragoza, 1993, pp. 445-456; véanse también los trabajos recogidos en LEMEUNIER, Guy: Los señoríos murcianos, siglos XVI-XVIII, Murcia, 1998), y se pusieron las bases para que algunos (caso de los Ferro) alcanzaran un título nobiliario en la centuria siguiente.

${ }^{25}$ Como muy bien ha señalado Vicente Montojo, si en la segunda mitad del XVI se acusa una incipiente inmigración italiana en el Levante español, de composición mayoritaria genovesa, es el periodo de paz del reinado de Felipe III cuando se observa una afluencia aún mayor: MONTOJO MONTOJO, Vicente: «Guerra y paz bajo Felipe III: el comercio del Levante español y sus relaciones clientelares, familiares y profesionales», en Chronica Nova (Granada) 31 (2005), pp. 349-387.

26 Velasco HernándeZ, Francisco: «El auge económico de Cartagena y la revitalización del sureste español en los siglos XVI y XVII», en Hispania (Madrid) 220 (2005), pp. 485-514; Montojo Montojo, Vicente: «Matrimonio y patrimonio en la oligarquía de Cartagena (siglos XVI-XVII)», en CHACÓN JimÉNEZ, Francisco et al. (ed.): Familias, grupos sociales y mujer en España (siglos XV-XIX), Murcia, 1991, pp. 49-93.

${ }^{27}$ Véase, a este respecto, RUIZ MARTíN, Felipe: Los alumbres españoles: un índice de la coyuntura económica europea en el siglo XVI, Madrid, 2005; y FrANCO SILVA, Alfonso: El alumbre del Reino de Murcia, Murcia, 1996.

${ }_{28}$ Montojo Montojo, Vicente: «La burguesía mercantil en el sureste español, el ejemplo de Cartagena» en ENCISO RECIO, Luis Miguel (coord.): La burguesía..., ob. cit., III, pp. 659-669; Montojo Montojo, Vicente, «El comercio con Andalucía Oriental, actividad de los mercaderes de Cartagena (siglos XVI-XVII)», en Chronica Nova (Granada) 24 (1997), pp. 237-252; MONTOJO Montojo, Vicente y RuIz IbÁÑEZ, José Javier: Entre el lucro y la defensa. Las relaciones entre la Monarquía y la sociedad mercantil en Cartagena. (Comerciantes y corsarios en el siglo XVII), Murcia, 1998, pp. 45-81; TORRES SÁNCHEZ, Rafael: «La colonia genovesa en Cartagena durante la Edad Moderna», en BELVEDERI, Raffaele (ed.): Il Congresso Internazionale..., ob. cit., pp. 553-581; VelasCO HernÁNDEZ, Francisco: Comercio y actividad portuaria en Cartagena (1570-1620), Murcia, 1989; Velasco HernándeZ, Francisco: «Capitalismo y burguesía mercantil, el puerto de Cartagena en el periodo de 1560-1630», en Contrastes (Murcia) 5-6 (1990), pp. 21-35.

${ }_{29}$ Montojo Montojo, Vicente: «Las relaciones comerciales entre el Sureste español y América a finales del siglo XVI y principios del XVII», en VILAR RAmíreZ, Juan Bautista (ed.): Murcia y América, Murcia, 1992, pp. 79-106.

30 Buena muestra de ello es que, entre finales del siglo XVI y principios del XVII, varias familias genovesas accedieron al concejo cartagenero, véase MonTOJo MonTojo, Vicente: «Matrimonio y patrimonio...», ob. cit., p. 53.

${ }^{31}$ La casi continua llegada de genoveses a poblaciones murcianas contrasta con lo ocurrido en otras ciudades castellanas que, tradicionalmente, habían tenido una nutrida comunidad ligur. Así ocurre, por ejemplo, en la ciudad de Granada, donde el número de genoveses disminuye durante el siglo XVI, hasta casi desaparecer en el XVII. Véase GARZÓN PAREJA, Manuel: La industria sedera en España. El arte de la seda en Granada, Granada, 1972, p. 332. 
vez con mayor regularidad, van a ser destinados a la ciudad de Murcia en vez de quedar en Cartagena.

La razón es un producto que, aunque está llamado a ser la base de las grandes fortunas de los comerciantes de origen genovés en la centuria del seiscientos, parece no haber despertado el interés de éstos hasta finales del siglo XVI: la seda.

En efecto, aunque desde mediados del siglo XVI los mercaderes genoveses son los principales encargados de distribuir en el Reino de Murcia productos manufacturados séricos — rasos, terciopelos, pasamanos- procedentes sobre todo de la propia Génova ${ }^{32}$, no es hasta finales de ese siglo cuando comienzan a enviar hacia los puertos italianos y franceses ${ }^{33}$ la seda en bruto que se produce en la huerta de Murcia. De hecho, aunque las actividades económicas que realizan los ligures afincados en Murcia durante el siglo XVII son muy diversas, van a tener como eje esencial la compraventa de seda ${ }^{34}$.

Desde finales del siglo XVI y hasta, al menos, mediados del siglo XVII - cuando son relevados, en parte, por mercaderes de origen portugués ${ }^{35}$ los comerciantes de origen genovés se convierten en los principales tratantes de seda murciana.

Para ello constituyen sociedades mercantiles no muy poderosas - aunque alguna enviaba seda y tejidos sederos a las Indias ${ }^{36}$ _, que eran más bien empresas o asociaciones familiares en las que participaban hermanos, primos, so-

32 Durante la segunda mitad del siglo XVI y primeras décadas del seiscientos entran por Cartagena importantes fletes de productos manufacturados séricos, tejidos que son distribuidos a distintas ciudades de Murcia y Castilla. Véase Velasco Hernández, Francisco: Comercio..., ob. cit., p. 86.

33 En el último tercio del siglo XVI gran cantidad de naves transportan la seda murciana hacia Livorno, pero el puerto terminal de la seda murciana es Alicante. BRAUDEL, Fernand y ROMANO, Ruggiero: Navires et marchandises à la entrée du port de Livourne (1547-1611), Paris, 1951.

34 Miralles Martínez, Pedro: La sociedad de la seda. Comercio, manufactura y relaciones sociales en Murcia durante el siglo XVII, Murcia, 2002, vv. pp.; Miralles MarTíneZ, Pedro: «Familias genovesas afincadas en Murcia vinculadas al negocio sedero», en VILLAR GARCIA, Begoña y PeZZI Cristobal, Pilar (eds.): Los extranjeros..., ob. cit., I, pp. 493-503.

35 A partir de 1653, y coincidiendo con el distanciamiento entre Génova y la Monarquía Hispánica (lo que para muchos marca el fin del «siglo de los genoveses»: sobre dicho término véase Ruiz Martín, Felipe: Pequeño capitalismo, gran capitalismo. Simón Ruiz y sus negocios en Florencia, Barcelona, 1990, p. 12; sobre las fechas que limitan dicha etapa, véase BraUdEL, Fernand: El Mediterráneo y el mundo mediterráneo en tiempos de Felipe II, Madrid, 1993, pp. 662), se produce un cambio en la importancia que tienen los tratantes sederos foráneos, cuyos porcentajes de mercado bajan considerablemente, mientras los comerciantes murcianos tienen una mayor preponderancia en la compraventa de seda. Empero, dentro de esos mercaderes locales estaban los genoveses y portugueses que se avecindan para disfrutar de ventajas fiscales: MiralLES MARTínEZ, Pedro: «Familias genovesas...», ob. cit., pp. 493-503; Miralles MARTíneZ, Pedro: «Mercaderes portugueses en la Murcia del siglo XVII», en Villar García, Begoña y PeZzi Cristóbal, Pilar (eds.): ob. cit., I, pp. 505-517.

36 Archivo Histórico Provincial de Murcia (AHPM), protocolo (prot.) 1821, 1685-II-25, folios (ff.) 60 recto (r)-62 verso (v); prot. 1823, 1690-III-6, ff. 129 r-134 v. 
brinos... ${ }^{37}$. Unas empresas familiares en las que, en ocasiones (sobre todo cuando pretenden llevar a cabo negocios de considerable volumen o de media y larga distancia ${ }^{38}$ ), no van a tener reparo en integrar temporalmente, como socios, a otros comerciantes genoveses o parientes murcianos, al igual que no dudan en buscar el apoyo de parientes o conciudadanos establecidos en otras plazas comerciales ${ }^{39}$ para lograr sus propósitos. Es decir, un «sistema de empresas» que en nada o muy poco se diferencia del utilizado por otros grupos genoveses establecidos en otras áreas peninsulares ${ }^{40}$.

En la segunda mitad del siglo XVII la colonia genovesa instalada en Murcia se encuentra «entrañablemente unida» ${ }^{41}$ : los fuertes lazos de relación y de solidaridad ${ }^{42}$ (basados en el paisanaje y la identidad profesional) que les unen facilitan que controlen buena parte del comercio de la seda. Las familias Ferro, Verdín, Mombello, Mayoli, Ginovino, Squarzafigo, Dardalla, Dhigueri, Piani, Vigo... crearon en la Murcia del seiscientos una tupida red de relaciones ${ }^{43}$, con

37 Montojo Montojo, Vicente: «La burguesía mercantil...», ob. cit., pp. 666-667.

38 Esta estrategia la utilizaron desde el siglo XVI. Molina MolinA, Ángel Luis: «Mercaderes genoveses...», ob. cit., p. 28.

39 Las familias más pujantes disponen de una densa red de agentes, representantes y procuradores en los principales lugares de la península, e incluso, sus tentáculos llegan hasta el Nuevo Mundo. Cuando no pueden disponer de sus familiares para realizar estas tareas de mediación, buscan alianzas con familias e individuos de su nación. Familia y nación constituían el cimiento de la organización comercial genovesa, de la empresa mercantil, muchas veces estructurada en forma de compañías comerciales con familiares residentes en otras ciudades: Cartagena, Madrid, Granada, Sevilla, Alicante y hasta en América. AHPM, prot. 1363, 1669-IV-9, ff. 12 r-14 v.; prot. 1252, 1673-IX-15, ff. 99 r-v.; MONTOjo MONTOJO, Vicente: «Las relaciones comerciales...», ob. cit., p. 93.

40 Franch Benavent, Ricardo: «Los genoveses en la España...», ob. cit., pp. 659-662; RODRÍGUEZ DE GRACIA, Hilario: «Mercaderes y asociaciones mercantiles en el comercio toledano de la seda en la segunda mitad del siglo XVII», en Hispania (Madrid) 210 (2002), pp. 65-112; ANDÚJAR CASTILlO, Francisco: «Los genoveses en el Reino de Granada: comercio y estrategias mercantiles», en BeLENGUER, Ernest (coord.): Felipe II y el Mediterráneo, Madrid, 1999, pp. 357-376.

41 Candel Crespo, Francisco: Familias genovesas en Murcia (Verdín, Ferro, Dardalla, Mayoli y Braco). Siglos XVII al XIX, Murcia, 1979, p. 80, nota 57.

${ }_{42}$ Como muy bien ha señalado Antonio Campillo, «Las sociedades humanas son entramados de relaciones sociales que se entretejen unas con otras de forma inseparable. En ese entramado no es posible encontrar ninguna relación social que ejerza una primacía absoluta sobre todas las otras...», CAMPILlo, Antonio: "Cuatro tesis para una teoría de la historia» en BArros, Carlos (ed.): Historia a Debate, La Coruña, 2000, p. 22-38.

43 Miralles MartíneZ, Pedro: Seda, trabajo y sociedad en la Murcia del siglo XVII, Murcia, 2000, pp. 424-479. Sobre el concepto de red social véanse: BotT, Elisabeth: Familia y red social, Madrid, 1990; Imízcoz BeunZA, José María: «Actores sociales y redes de relaciones en las sociedades del Antiguo Régimen», en Historia a debate, Santiago de Compostela, 1987, pp. 341353; Imízcoz BeunZA, José María: «Comunidad, red social y elites. Un análisis de la vertebración social en el Antiguo Régimen», en ImízCOZ, J. M. (dir.): Elites, poder y red social. Las elites del País Vasco y Navarra en la Edad Moderna, Vitoria, 1996, pp. 13-50; Pro RuIZ, Juan: «Las elites de la España liberal, clases y redes en la definición del espacio social (1808-1931)», en Historia Social (Valencia) 21 (1995), pp. 47-69; donde incluye una selecta bibliografía. Para una aplicación del 
unos lazos humanos, familiares, económicos, sociales, culturales y religiosos, inextricables, producto de alianzas familiares y de solidaridades de tipo nacional y económico. No sólo el padre apoyaba al hijo, sino que el tío amparaba al sobrino y el paisano al compatriota ${ }^{44}$.

Sin embargo, tal vez lo más interesante (si bien es cierto que, en este sentido, poco se diferencian de los instalados en otras ciudades españolas ${ }^{45}$ ) es que los genoveses de la Murcia del seiscientos, a la vez que conservaron la cohesión propia de una nación extranjera ${ }^{46}$, lograron insertarse en la sociedad murciana. Buena muestra de ello puede verse en el uso dado por éstos a los beneficios obtenidos en su actividad comercial. En efecto, parte de las ganancias son reinvertidas en el tráfico de seda y otras materias primas, pero una porción considerable de ellas son invertidas en bienes que poco tienen que ver con el comercio: tierras, cargos municipales, constitución de capellanías, obtención de hidalguías y otros honores de tipo estamental.

Por término general, suele observarse un cambio en lo referente al uso de los beneficios procedentes de la actividad comercial dependiendo del tiempo que la familia esté establecida - y por tanto se involucre- en la sociedad local receptora. Así, la primera generación, la que se instala en la ciudad, suele ser la que realiza negocios arriesgados como enviar seda y tejidos a América; interviene de forma directa también en la fabricación de tejidos, además del torcido y teñido de la seda ${ }^{47}$; y está plenamente involucrada en el movimiento especu-

concepto de red social en Murcia véase la tesis doctoral inédita IRIGOYEN LóPEZ, Antonio: Entre el cielo y la tierra. Entre la familia y la institución, Murcia, 1998, especialmente el capítulo II.

44 Miralles MartíneZ, Pedro: «Familias genovesas...», ob. cit., pp. 493-503.

${ }^{45}$ Son muy numerosos los ejemplos a este respecto. Véanse, por ejemplo, LóPEZ DE COCA, José Enrique y Beltrán, María Teresa: «Mercaderes genoveses en Málaga (1487-1516): los hermanos Centurión e Ytalián», en Historia, Instituciones, Documentos (Sevilla) 7 (1980), pp. 95-124; IGLESIAS NÚÑEZ, Francisco Javier: «Prácticas mercantiles y estrategias familiares de los genoveses: Almería, siglo XVIII», en Chronica Nova (Granada) 29 (2002), pp. 141-178; PeLLEGRINI, Sandro: «Los genoveses en España: la colonia de Cádiz», en Boletín de la Real Sociedad Geográfica (Madrid) 139-140 (2003-2004), pp. 137-174 (artículo en el que se puede encontrar, además, una nutrida bibliografía sobre el tema); así como las obras ya citadas de IGUAL, David y NAVARRO, Germán: Los genoveses...; y los trabajos recogidos en Los extranjeros en la España..., ob. cit.

46 Montojo Montojo, Vicente y Ruiz IbáÑez, José Javier: ob. cit., p. 38.

${ }^{47}$ Aunque no realizaban grandes inversiones en la manufactura textil sedera, hemos encontrado varios casos de mercaderes que tuercen, tiñen y tejen la seda para enviarla incluso hasta América. De manera que sí invirtieron en la manufactura murciana, sobre todo en el torcido de la seda (el primer tratamiento manufacturero de ésta, que hace aumentar considerablemente su valor) que más tarde envían a los centros manufactureros peninsulares y a América. En el tejido de ésta se limitan a los productos más sencillos — tafetanes - que son elaborados por tejedores murcianos dependientes de ellos, y que más tarde se encargan de comercializar. En este sentido, los genoveses asentados en Murcia se diferencian de los instalados en otro de los grandes centros sederos hispánicos, como Valencia, donde los mercaderes ligures no se dedican a la manufactura sedera. FRANCH BENAVENT, Ricardo: «Dinastías comerciales genovesas...», ob. cit., pp. 301 y 305. 
lativo del dinero ${ }^{48}$ (sobre todo como prestamistas). De hecho, la mayor parte del patrimonio de estos «recién llegados» suele estar compuesta por bienes muebles: seda, tejidos, créditos, dinero en metálico, etc. Son las generaciones posteriores quienes comienzan a convertir, poco a poco, esos bienes muebles en bienes raíces ${ }^{49}$ y elementos honoríficos, transformando también, en muchos casos, su actividad económica y profesional: en tres, o a lo sumo, cuatro generaciones $^{50}$, las familia mercantiles pasan a convertirse en terratenientes ${ }^{51}$.

Evidentemente, se trata de la clásica evolución promocional dentro de una sociedad estamental: abandono de una actividad muy rentable en términos económicos pero que desprestigiaba en términos sociales, para abrazar otra (el absentismo terrateniente) de corte diametralmente opuesto ${ }^{52}$. Sin embargo, en el caso que nos ocupa, esta transformación radical de las actividades económicas de estas familias no parece ser necesaria para ascender socialmente: buena parte de los comerciantes genoveses afincados en Murcia logran ser admitidos como hidalgos en la primera generación (y lo que tal vez sea más importante, pese a su manifiesta actividad comercial, raramente se puso en tela de juicio su nobleza), algunos logran acceder al cabildo municipal previa compra de oficios concejiles (incluso, como veremos a continuación, puntualmente llegan a formar parte de instituciones superiores), y la mayor parte de ellos mantienen buenas relaciones con las familias que conforman la oligarquía (cuando no la elite ${ }^{53}$ ) local murciana.

48 Este interés por la actividad financiera y crediticia que también se observa entre la comunidad genovesa toledana: RODRíGUEZ DE GRACIA, Hilario: «Mercaderes y financieros. Los genoveses de Toledo entre 1561 y 1621», en Los extranjeros en la España..., ob. cit., pp. 597-610.

${ }^{49}$ De principios del siglo XVI hay algunos testimonios de esto. Molina MOLINA, Ángel Luis: «Mercaderes genoveses...», ob. cit., p. 28. En Cartagena, a principios del siglo XVII, algunos genoveses forman compañías para construir molinos harineros, invirtiendo por tanto en la transformación de los productos agrícolas. MONTOJO MONTOJO, Vicente: «Mercados y estrategias mercantiles en torno a Cartagena en el siglo XVI y la primera mitad del XVII: un microanálisis», en Cuadernos del Estero (Cartagena) 7-10 (1992-1995), p. 143-202, pp. 195-196.

50 Algo que también ocurre en el caso de los comerciantes genoveses de Cartagena: Velasco HERNÁNDEZ, Francisco: «Lazo familiar, conexión económica e integración social: la burguesía cartagenera de origen extranjero en el siglo XVII», en CHACón, Francisco y FERRER, Llorenç (eds.): Familia, casa y trabajo, Murcia, 1997, p. 233; véase también de este autor «Comportamientos y estrategias socio familiares de la burguesía mercantil de Cartagena en los siglos XVI y XVII», en IrIGOYEn, Antonio y PÉREZ, Antonio (eds.): Familia, transmisión y perpetuación (siglos XVI-XIX), Murcia, 2002, pp. 221-240.

${ }^{51}$ Si bien es cierto que, en el caso de los genoveses establecidos en la ciudad de Murcia, para ello habrá que esperar al siglo XVIII. CANDEL CRESPO, Francisco: Familias genovesas en Murcia..., ob. cit., pp. 26 y 28.

52 Morales Moya, A: «Actividades económicas y honor estamental en el siglo XVIII», en Hispania (Madrid) 167 (1987), 951-976.

53 Sobre la diferencia entre elite y oligarquía locales, véase Molina PUCHE, Sebastián: «Elite local: análisis de un concepto a través de las familias de poder del corregimiento de VillenaChinchilla en el siglo XVII», en Estudis (Valencia) 31 (2005), pp. 197-222. 
Honor, poder, relaciones sociales y, cómo no, dinero —que, a la postre, es el elemento que ha posibilitado la adquisición de los anteriores_- Aparentemente, las familias de origen genovés asentadas en Murcia cuentan con todas las variables necesarias para ocupar el vértice de la sociedad local sin necesidad de abandonar su actividad comercial. Sin embargo, en la mayor parte de los casos estudiados, las dinastías de mercaderes acabarán por renunciar al comercio.

La adopción del modo de vida del grupo social dirigente, ¿debemos verla como un ejemplo de "traición de la burguesía» o se trata más bien de una estrategia de promoción social? Como podremos observar en las páginas siguientes por medio del análisis prosopográfico del itinerario social de la familia Ferro Verdín (la más destacada familia comerciante de origen genovés de la ciudad de Murcia a lo largo de los siglos XVII y XVIII), la respuesta parece estar más próxima a un intento por lograr el reconocimiento y aceptación social del grupo al que se intenta acceder, que una simple razón de mimetismo. Como veremos a continuación, para conseguir la integración en el grupo de poder -es decir, para considerar que realmente se ha ascendido socialmente hasta la cima de la sociedad local — no es suficiente adquirir las señas de identidad del grupo, hay que contar con el reconocimiento de sus componentes.

\section{UN LARGO CAMINO DE LA TIENDA DE SEDAS AL TÍTUlO NOBILIARIO. LA FAMILIA FERRO VERDÍN}

A comienzos del siglo XVII se instala en la ciudad de Cartagena, procedente de Varazze, Juan Bautista Verdín Carro. En esos momentos Cartagena es un destino muy interesante para individuos emprendedores como Juan Bautista: cuenta con una excelente localización frente a las principales rutas marítimas, amplias exenciones fiscales, y su hinterland ofrece muchos productos con los que comerciar con el exterior (alumbre, barrilla, esparto, jabón, seda), así como un amplio mercado en el que introducir manufacturas y objetos de lujo ${ }^{54}$. Pero además, resulta especialmente atractivo para los inmigrantes procedentes de Génova, pues en la ciudad portuaria se ha formado un numeroso y, sobre todo, influyente — recordemos que, desde finales del siglo XVI, varias familias genovesas logran acceder al concejo ${ }^{55}$ - colectivo ligur que suele facilitar la instalación de conciudadanos en Cartagena.

54 Velasco HernándeZ, Francisco: El nuevo resurgir de Cartagena entre 1540 y 1676, Murcia, 2001, pp. 15 y sgts; también de este autor: «Comportamiento y estrategias sociofamiliares...», ob. cit., p. 225.

55 El primer regidor de origen genovés es Pedro Casanova, que accede al concejo en 1580. A partir de ese momento, le seguirán muchos otros (Francisco Bosso, Alexandro de Marco, Tomás Digueri...), hasta el punto que, a mediados del siglo XVII, no menos del $40 \%$ del concejo cartagenero esté compuesto por miembros de la burguesía mercantil de origen extranjero: véase VELASCO HERNÁNDEZ, Francisco: «Comportamiento y estrategias...», ob. cit., p. 233-234; también Montojo Montojo, Vicente: El Siglo de Oro de Cartagena..., ob. cit., pp. 251 y sgts. 
Aunque la llegada de Juan Bautista Verdín a la ciudad portuaria no parece responder a la llamada de ningún pariente o convecino previamente instalado en ella ${ }^{56}$, en modo alguno puede ser considerada como una mera aventura personal: a tenor de su trayectoria personal en ese nuevo destino, debió contar con la decidida ayuda de la comunidad genovesa o, al menos, de algún sector de la misma, pues de lo contrario una promoción profesional y social tan rápida como la que protagoniza se antoja poco menos que imposible.

En efecto, antes de 1620 ya cuenta con su propia tienda de sedas ${ }^{57}$, logra ejercer el cargo de gentilhombre de la artillería de Cartagena ${ }^{58}$ y lo que es más importante: ese mismo año realiza un matrimonio ventajoso con Beatriz de Molina Aguado59, hija de Alonso de Molina, mercader procedente de Albacete y secretario del Santo Oficio de Murcia ${ }^{60}$.

Evidentemente, se trata de un considerable salto social para un inmigrante recién llegado: en pocos años ha logrado abrirse camino en el mundo de los negocios, ha sido reconocido como miembro de pleno derecho del estamento noble, y ha conseguido emparentar con una familia que le ha de facilitar la entrada en el Santo Oficio — es nombrado familiar en $1630^{61}$ _ , una institución que otorga poder y diferenciación social ${ }^{62}$. Toda una serie de hitos que nos

56 No aparecen muestras de ello: no tenemos noticia de que tuviera una relación comercial o profesional preferente con ninguna de las familias genovesas establecidas en Cartagena, ni tampoco hay indicios de que tuviera con alguna de éstas una relación clientelar o de obligación personal. De igual modo, resulta sintomático el hecho de que tuviera tienda propia —es decir, que no trabajara al servicio de un comerciante mayor_-, y que, a la hora de tomar esposa, prefiriera a la hija de un mediano mercader nativo (endogamia profesional) en vez de una mujer de origen genovés (endogamia geográfica, sin lugar a dudas, la opción matrimonial más común entre las comunidades extranjeras o minoritarias que pretenden mantener su identidad, tales como los propios comerciantes genoveses: véase, por ejemplo, VELASco HERNÁNDEZ, Francisco: «Lazo familiar, conexión económica...», ob. cit.; o la comunidad judeoconversa: HUERGA CRIADO, Pilar: «La familia judeoconversa», en CASEY, James y HernándeZ FranCO, Juan: Familia, parentesco y linaje, Murcia, 1997, pp. 151-164).

57 Montojo Montojo, Vicente: Cartagena en el Siglo..., ob. cit., pp. 250 y 255; CANDEL Crespo, Francisco: Familias..., ob. cit., p. 13.

58 Archivo Municipal de Murcia (AMM), Cartas Reales (CC RR) 1688, ff. 540 r-v. lo que supone, por un lado, haber logrado el avecindamiento en la ciudad, y por otro, que el concejo le haya reconocido su nobleza, pues el cargo señalado sólo puede ser ejercido por hidalgos: véase Montojo Montojo, Vicente y RuIz IbÁÑEZ, José Javier: Entre el lucro y la defensa..., ob. cit.

59 AMM, CC RR 1687, f. 537 v.

60 Un cargo que, en 1642, consigue vincular a su familia durante cuatro generaciones: ese año logra que su hijo - Alonso de Molina - fuera nombrado «notario de secretos del Santo Oficio» además de poder «nombrar otras tres vidas, las que por bien tubiere, que le sucedan en el dicho oficio». AMM, CC RR 1687, ff. 562 v-569 r.

61 AMM, CC RR 1687, ff. 552 r-555 r.

${ }^{62}$ Nos referimos, evidentemente, a la diferenciación social que supone el reconocimiento explícito de contar con sangre limpia, requisito que han de demostrar todos los familiares del Santo Oficio: véase CERrillo Cruz, Gonzalo: Los familiares de la Inquisición española, Valladolid, 2000. De hecho, tras 
llevan a colegir que debía contar con algún valedor (o valedores) en la ciudad que le allanase el camino en asuntos tales como la adquisición de la vecindad o el reconocimiento de su nobleza.

Pese a su buena situación en Cartagena, en el año 1632 Juan Bautista traslada su residencia a la ciudad de Murcia, tal vez siguiendo a su suegro, que se desplaza a la ciudad en la que debía llevar a cabo sus labores como escribano del secreto del Santo Oficio ${ }^{63}$, o tal vez a la búsqueda de mayores beneficios comerciales. Sea como fuere, ese año estaba ya asentado definitivamente en la ciudad de Murcia, eso sí, gozando del reconocimiento de hidalgo ${ }^{64}$. Ahora bien, se trata de un hidalgo atípico, pues en la documentación del Contraste de la Seda de 1634 aparece registrado pesando 203 libras de joyante ${ }^{65}$, que un año más tarde incrementa hasta las 658 libras $^{66}$. Estas cifras dan muestra de la buena marcha de los negocios de Juan Bautista Verdín, unos negocios centrados principalmente en la seda, y que harían de él un individuo muy bien situado económicamente.

Sin embargo, tal vez lo más interesante sea analizar qué hace Juan Bautista con los beneficios obtenidos con dicho mercadeo. Y a tenor de lo que nos indican tanto él como su esposa en sus testamentos ${ }^{67}$, parece que el matrimonio Verdín Molina tenía muy claro cuál debía ser el destino de dichas ganancias: acrecentar el prestigio social de la familia.

En efecto, Juan Bautista Verdín va a tomar una serie de decisiones en las cuales se puede observar, con una claridad meridiana, su interés por potenciar la faceta «honorable» de la familia al tiempo que intenta alejar a ésta de la innoble actividad comercial que ha ejercido.

En este sentido se ha de entender la adquisición, poco después de haberse instalado en Murcia, de la capilla de San Pedro Nolasco en el convento de la Merced $^{68}$ para ser utilizada como lugar de enterramiento de los miembros del linaje Verdín Molina: evidentemente, se trata de una inversión en capital simbólico muy alejado de toda búsqueda de rendimiento económico.

Pero resulta mucho más significativa e ilustrativa la política matrimonial y «profesional» que sigue con sus hijos, pues denota claramente la convicción de

ser nombrado familiar del Santo Oficio, Juan Bautista se apresura en conseguir para su hija Josefa y para hijo Francisco sendos certificados de limpieza de sangre: AMM, CC RR. 1688, f. 609 r.

${ }^{63}$ De hecho, se va a instalar en una casa propia contigua a la de su suegro, sita en la parroquia de San Pedro, AMM, CC RR. 1687, ff. 575 v-576 v.

${ }^{64}$ Como tal aparece registrado Juan Bautista Verdín en el padrón de moneda forera de ese año: AMM, CC RR. 1687, ff. 561 r-v.

${ }^{65}$ La joyante es la seda de más calidad. A.M.M., libro del Contraste de 1634.

66 AMM, libro del Contraste de 1635.

67 AMM, CC RR 1687, ff. 534 v-546 r. Juan Bautista Verdín muere entre 1650 y 1654 (CANDEl CRESPO, Francisco: Familias..., ob. cit., p. 15).

68 Se les autorizó a hacer obras en la capilla para que ésta dé al altar mayor de la ermita. AMM, CC RR 1687, ff. 575 v-576 v. 
Juan Bautista Verdín de separar la que ha sido su principal fuente de ingresos de las que han sido sus principales fuentes de honor.

Padre de seis hijos (Francisco, Nicolasa, Josefa, Dorotea y Jerónima), dejará los negocios en manos de su yerno, Antonio Ferro Herguero, también natural de Varazze ${ }^{69}$, quien ha casado en 1640 con Nicolasa, hija mayor del matrimonio Verdín Molina. El resto de sus hijos son alejados del comercio. Francisco, su único hijo varón, es destinado a la iglesia, donde protagoniza una carrera meteórica: desde sus inicios como canónigo ${ }^{70}$ en Murcia, llegará a ser gobernador y vicario general de la diócesis de Plasencia y, más tarde, obispo de Guadalajara (Nueva España, en 1665) y Michoacán $\left(1672^{71}\right)$. Sus hijas menores, Dorotea y Jerónima, son apartadas de la vida mundana (y también de la herencia fami$\operatorname{liar}^{72}$ ) e ingresan igualmente en religión: ambas profesarán en el convento de Madre de Dios de Murcia, donde llegan a ser abadesas ${ }^{73}$. Por último, su hija Josefa parece ser la elegida para conectar, vía matrimonial, con el grupo dirigente local, al menos con el segmento más modesto del mismo: dotada considerablemente por su padre, casará sucesivamente con el alguacil mayor del Santo Oficio Jerónimo de Arce y Reinoso ${ }^{74}$, y tras enviudar, con don Baltasar

${ }^{69}$ Hijo de Juan Bautista Ferro y Antonia Herguero, de los que fue su único heredero (AMM, CC RR 1687, f. 499 v.). Su itinerario es parecido al seguido, años atrás, por su propio suegro: instalado inicialmente en Cartagena, donde es nombrado gentilhombre de artillería por el Consejo de Guerra y, por lo tanto, catalogado como hidalgo. Más tarde pasa a Murcia, donde pone tienda de tejidos, en la que además de vender productos textiles, daba créditos a vecinos de Murcia, Alhama, Blanca, Cieza (AHPM, prot. 1283, 1648-I-21, ff. 34 r-v.; 1648-VIII-19, ff. 382 r-v). Con todo, es su oportuno matrimonio con Nicolasa Verdín Molina el que le convertirá en un próspero hombre de negocios y le llevará a obtener los cargos de Síndico del Convento de Padres Capuchinos y Director del Pósito de Murcia: Candel Crespo, Francisco: Familias..., ob. cit., pp. 17-19.

${ }^{70}$ De hecho, si llega a ser canónigo de la iglesia catedral es gracias a que sus padres le hacen objeto de un adelanto de ambas legítimas para que siga sus estudios y para comprar dicha canonjía: AMM, CC RR 1687, ff. 534 v-546 r. Véase también IRIGOYEN LÓPEZ, Antonio: Entre el cielo y la tierra..., ob. cit., pp. 505-525.

${ }^{71}$ Sobre este personaje véanse: CANDel Crespo, Francisco: «Don Francisco Verdín de Molina. Un obispo murciano en el Méjico virreinal», en Murgetana (Murcia) 36 (1971), pp. 37-60; CANDEL CRESPO, Francisco: Historia de un convento murciano. El de Justinianas de Madre de Dios (1490-1975), Murcia, 1977, pp. 145-146; CANDel Crespo, Francisco: «Don Francisco Verdín de Molina, obispo de Guadalajara y Michoacán, un ilustre desconocido cartagenero», en Idealidad (Murcia) s. n. (1974), pp. 193-194.

${ }^{72}$ Dorotea y Jerónima son excluidas de las herencias paterna y materna previa concesión de una renta de 50 ducados anuales: AMM, CC RR 1687, ff. 534 v-546 r.

${ }^{73}$ Las dotes conventuales ascienden a 800 ducados a cada una. Los 1.600 ducados son impuestos como censo, a favor del convento, sobre 60 tahúllas de moreras que Juan Bautista tenía en Caravija. Las escrituras se hicieron el 28-I-1647 y el 17-II-1650. AHPM, prot. 792, 1669-XI-5, f. 391 r; prot. 1308, 28-I-1647, ff. 62 r-67 v. Esto nos indica que el capital que iba acumulando Juan Bautista Verdín con los negocios sederos lo invertía, además de en ir situando en puestos de prestigio a sus hijos e hijas, en tierras.

74 AMM, CC RR 1687, ff. 556 v-560 r. 
Fontes de Albornoz, miembro (si bien es cierto que no especialmente destacado) de una rama secundaria un noble y antiguo linaje de la ciudad ${ }^{75}$.

La lógica de Juan Bautista Verdín parece estar bien clara: aunque el dinero que ha obtenido del comercio es el que le ha permitido medrar, intenta borrar las huellas más visibles que puedan mostrar esa procedencia mercantil. Al ceder a su yerno el negocio ${ }^{76}$ desvincula su apellido (ahora serán Ferro los mercaderes, no Verdín) de una actividad que desprestigiaba. Así su hija Josefa, en quien pone todas sus esperanzas de integración en la oligarquía murciana, se convierte en la cuñada de un comerciante, no en la hermana de uno de ellos.

Es cierto que al obrar de esta manera (centrando sus esfuerzos principalmente en una de sus hijas y condenando a su único hijo varón a no poder dejar descendencia legítima por su condición clerical) parece sacrificar el mantenimiento de su apellido en aras de la integración de parte de sus descendientes en la elite local.

Visto desde cierta perspectiva, la elegida se muestra como una de las mejores opciones con las que podía contar: en el mercado matrimonial una mujer fuertemente dotada contaba con mayores probabilidades de ser bien recibida (y, por tanto, más posibilidades de «casar hacia arriba») que el hijo de un comerciante extranjero, por muy reconocida que tuviera su nobleza. Y por el contrario, la carrera eclesiástica se mostraba como una de las mejores vías para obtener honor, poder - y por qué no decirlo, también riqueza - para el hijo de un mercader.

A la muerte de Juan Bautista (acaecida entre 1650 y 1654) su estrategia de integración en la elite local $-\mathrm{O}$ al menos aproximación a ella- va a ser continuada por su hijo: el año 1667, siendo obispo de Guadalajara, funda el llamado «vínculo Verdín», el cual será acrecentado, en 1672, con otros dos mayoraz$\operatorname{gos}^{77}$. La primera beneficiaria no va a ser otra que doña Josefa Verdín ${ }^{78}$, dejando totalmente de lado a su hermana mayor Nicolasa. La mujer de un mercader no parece ser merecedora de un vínculo que contiene bienes (tierras en la huerta, censos, un oficio de regidor perpetuo de la ciudad de Murcia) valorados en 4.000 pesos de oro $^{79}$.

75 AHPM, prot. 1826, 1678-III-23, ff. 27 r-36 v.; 1696-XII-15, ff. 187 r-188 v.; CANDEL CRESPO, Francisco: Familias..., ob. cit., p. 14. Sobre la familia Fontes: véase FONTES FUSTER, Enrique: Nuestra heráldica. (Historia de la familia Fontes y otras enlazadas con ella), Murcia, 1933.

76 Con el cual forma una compañía comercial: AMM, CC RR 1687, f. 540 v.

77 AHPM, prot. 1826, 1678-III-23, ff. 27 r-45 v., anexo.

${ }^{78}$ El obispo envía «...algunas cantidades de maravedís para que con ellas se comprassen propiedades, juros o censos y sobre ellos se ynpusiese vínculo y maiorazgo, patronato de legos para que sirviese de aumento de dote de la señora $\mathrm{D}^{\mathrm{a}}$ Jusepa Verdín y Molina...». AHPM, prot. 792, 1669-XI-5, ff. 390 r-396 v.

79 Con los cuales se compran, al menos, 172 tahúllas de morerales (AHPM, prot. 1826, 1696XII-14, ff. 148 r-174 v.; 1696-XII-15, ff. 178 r-215 v) y el regimiento de la ciudad de Murcia, adquirido por el canónigo Francisco Ferro (sobrino del obispo y por encargo de éste) por 30.000 reales, pagados al contado a la viuda del regidor Francisco Pérez de los Cobos en 1669 (AHPM, prot. 792, 1669-VIII-30, ff. 268 r-v.; prot. 792, 1669-XI-5, ff. 390 v-391 r). 
La decisión de don Francisco Verdín de fundar los mayorazgos a favor de su hermana no hacen más que reforzar las directrices marcadas por su padre: potenciar la rama familiar «honorable» y distanciarse de la que ha quedado con los negocios.

Aunque como más tarde veremos, las previsiones de Juan Bautista Verdín acabarán en saco roto por un motivo meramente biológico (doña Josefa muere sin dejar descendencia hacia 1681, con lo cual todos los bienes de la familia Verdín Molina, incluidos los vínculos del obispo de Michoacán, acaban recayendo en la rama Ferro Verdín), la estrategia de promoción social diseñada por éste va a crear escuela: su yerno, Antonio Ferro Herguero, va a seguir una estrategia muy parecida.

Gracias, en buena parte, al apoyo concedido por su suegro (y, suponemos, a su propia habilidad para los negocios), Antonio Ferro Herguero se convierte en uno de los comerciantes más ricos de la Murcia de mediados del seiscientos.

Dedicado principalmente a la compraventa de seda en rama y su manufactura, es uno de los mercaderes que más seda declaran en el Contraste, con la salvedad de que la seda la «tuerce» antes de enviarla fuera de Murcia ${ }^{80}$. Da un nuevo brío al negocio familiar al comenzar a invertir también en la manufactura de la seda en bruto: varios torcedores trabajaban a sus órdenes, y también varios tejedores y tintoreros que fabrican tafetanes para él ${ }^{81}$. Aunque muchos de estos tejidos sederos eran vendidos en la propia Murcia, una buena parte los lleva a Sevilla para exportarlos a América ${ }^{82}$. El genovés Antonio Ferro es, por tanto, un típico ejemplo de verleger en la Murcia del siglo XVII: una clara muestra de gran comerciante que controla todo el proceso de manufactura y comercialización de la seda y sus productos artesanales, y del que dependen maestros artesanos de diversos oficios.

Como no podía ser de otra manera, dicha dedicación comercial hace de Antonio Ferro Herguero un hombre muy rico. Cuando el año $1674^{83}$ se lleva a

${ }^{80}$ Por ejemplo, en 1660 toda la seda joyante que pesó en el Contraste era torcida. AMM, legajo 2740. Ya desde 1645 hay testimonios de sus relaciones con los artesanos sederos, y de su capacidad económica, por ejemplo, era el fiador del pasamanero Antonio de Alarcón, que había arrendado «la alcabala del viento aduana del tercio». AMM, legajo 2750/33.

${ }_{81} \mathrm{Al}$ realizar el inventario de sus bienes se encontraron en su casa 1.098 varas de tafetanes y 33 libras de cochinilla. Parte de esos tafetanes estaban hechos en Murcia ya que Antonio Ferro proporcionaba seda y tintes a varios tejedores y tintoreros sederos. Así, el tejedor Jusepe Coloma tenía 34,5 libras de joyante teñida de rojo y negro, para tejer tafetanes; el tejedor Matías Eugenio 17,5 libras de joyante negra, y el tejedor Antonio Sancho, 36 libras de joyante para tafetanes negros. La cochinilla se la proporcionaba a los tintoreros para que tiñeran parte de su seda, la que posteriormente entregaba a los tejedores murcianos: AHPM, prot. 791, 1667-X-21, f. $373 \mathrm{v}$.

${ }^{82}$ A su muerte, tenía en poder de un vecino de Sevilla una partida de tafetanes valorada en 73.522 reales que había comprado a 10 y 12 reales la vara: AHPM, prot. 791, 1667-X-21, f. 371 v.

83 Antonio Ferro Herguero hizo testamento y falleció, en 1667, el inventario post mortem se comenzó a realizar el 18 de octubre del citado año. Testamento, AHPM, prot. 791, 1667-X-14, ff. 349 r-352 v; AMM, CC RR 1687, ff. 508 r-532 v. Inventario, AHPM, prot. 791, 1667-X-18, ff. 
cabo la partición de su herencia entre sus seis hijos vivos -Francisco, Juan Bautista, Antonio, Nicolasa, Mariana y María_ ${ }^{84}$, cada uno de ellos recibe bienes valorados en unos 93.000 reales $^{85}$. En total la fortuna amasada por Antonio Ferro - por obra y gracia del comercio sedero_- en poco más de 30 años, era superior a 50.000 ducados $^{86}$, nivel de riqueza que es comparable al de los grandes mercaderes cartageneros de la época ${ }^{87}$.

Sin embargo, y al igual que hiciera su suegro unos años antes, Antonio Ferro parece ser muy consciente de que, pese a su excelente posición económica, y pese a haber sido reconocido como hidalgo, carece casi totalmente de capital simbólico y honorífico.

Tal vez en un intento por paliar dicha carencia, y vistos los buenos resultados obtenidos por su suegro (recordemos que a mediados de la década de 1660 Francisco Verdín Molina ya ha sido nombrado obispo de Guadalajara, y se encuentran enlazados con una de las más antiguas familias nobles de la ciudad por medio de Josefa Verdín), adopta una estrategia familiar semejante a la diseñada por éste.

Así, Francisco, su hijo primogénito — nacido en Murcia en 1645—, va a ser encaminado hacia la carrera eclesiástica. A todas luces, la intención es aprovechar la influencia y redes de relación social de su tío Francisco Verdín. De hecho, ya en 1658, cuando contaba 13 años de edad, su tío Francisco aparece junto a Antonio Ferro solicitando a la Santa Sede que fuera nombrado coadjutor $^{88}$. Poco después, en 1665, ya era canónigo de la Catedral —una vez más gracias a su tío, a quien entra a sustituir-, juez de la Santa Cruzada y comisario para la fábrica del templo de Nuestra Señora de la Fuensanta ${ }^{89}$.

356 r-v.; 1667-X-19, ff. 357 r-374 r.; 1667-X-21, ff. 374 v-376 v. Su esposa hizo testamento en 1666 y falleció en julio de 1667, que fue cuando se realizó el inventario de sus bienes. AHPM, prot. 790, 1666-XI-7, ff. 444 r-446 v., testamento; prot. 790, 1666-XI-8, ff. 446 r-447 v., codicilo; prot. 791, 1667-VII-6, ff. 241 r-254 v., inventario.

84 «Hijuela de los bienes de Juan Ferro por partición de los bienes de sus padres Antonio Ferro y Nicolasa Verdín». AHPM, prot. 1826, 1674-II-16, ff. 235 v-249 r.

${ }^{85}$ Juan Bautista sumó a esta cantidad más de 17.000 reales de censos, y unos 600.000 maravedís más que sus hermanos, ya que se le dieron también dos censos para pagar al convento de Madre de Dios. AHPM, prot. 1826, 1674-II-16, ff. 79 r-92 v.

86 Sus bienes estaban valorados en 50.539 ducados (AHPM, prot. 1826, 1674-II-16, ff. 79 r92 v.). Por su inventario de bienes conocemos el lujo y la ostentación que vivió Antonio Ferro: 43 cuadros, 54 objetos de plata, 32 sortijas de oro, plata y piedras preciosas, otras 25 joyas diversas, un esclavo y una esclava, etc. Además, como ya hiciera su suegro años atrás, también invierte en bienes inmuebles: poseía 547 tahúllas de tierra en la huerta de Murcia, y en la calle Frenería tenía varias viviendas, algunas compradas al genovés Leandro Corvari.

87 Velasco HernándeZ, Francisco: La ícrisis del siglo XVII? ..., ob. cit., pp. 388-389.

88 Para reforzar dicha solicitud, Antonio Ferro y Francisco Verdín declaran que «...porque es necesario sustentarle de todo lo necesario durante el tiempo de la dicha coadjutoría hasta que llegue el caso de entrar en posesión de ella...», se obligaban a darle de sus bienes «todo aquello que fuere menester para su gasto, congrua y sustentación y de su familia», estudios incluidos: AHPM, prot. 786, 1658-XI-9, ff. 449 r-v.

89 AHPM, prot. 1826, 1695-I-26, f. 2 r.; AMM, AA CC 1695-I-25. 
Pero las similitudes con lo hecho por su suegro años atrás no acaban ahí: tal vez también con la intención de desligar a una parte de sus descendientes de la actividad comercial, tal vez con la idea de hallar un sucesor a la altura de la empresa, poco antes de morir en 1667 cede sus negocios no a uno de sus hijos (todos menores de edad en ese momento, con excepción del canónigo Francisco quien, por otra parte, nunca abandona totalmente el mundo de los negocios ${ }^{90}$ ), sino a su yerno ${ }^{91}$, Antonio Ferro Carnalla, casado con su hija mayor María Ferro ese mismo año ${ }^{92}$.

Vista la considerable dote ofrecida a María (nada menos que 7.100 ducados $^{93}$ ), es muy probable que Antonio Ferro Herguero no hubiera tenido demasiados problemas en encontrarle un marido perteneciente a la mesocracia local (un jurado, un familiar del Santo Oficio, tal vez un regidor). No obstante, Herguero prefiere optar por asegurar la continuidad de la principal fuente de ingresos de la familia. A diferencia de su suegro, no apuesta directamente por la honra. Al menos, no en ese momento: su fallecimiento nos deja con la incógnita de lo que tenía reservado para el resto de sus hijos.

El marido elegido para su hija es un viejo conocido de la familia, Antonio Ferro Carnalla, uno de esos parientes lejanos (llamaba a su suegro tío, aunque realmente no lo era) que son «llamados» para colaborar en la empresa familiar. Nacido en Varazze en $1632^{94}$, llega a Murcia muy joven, con unos catorce años ${ }^{95}$, y comienza a trabajar con su futuro suegro.

${ }_{90}$ Realiza intercambios, compras y ventas de tierras (una de sus compras más importantes fue la que hizo al racionero Julián Pérez de Ávila de 543 tahúllas con palacios, casa y bodega, en Cinco Alquerías, el año 1665, por 7700 ducados: AHPM, prot. 790, 1665-XII-17, ff. 499 r-511 v.); cosecha importantes cantidades de seda que comerciaba enviando fuera de Murcia (AMM, AA CC 1692-VII-28, f. 91 v.); vende hoja de morera y presta dinero para beneficiarla a cambio de seda, comercia con sosa y barrilla (AHPM, prot. 1822, 1687-II-27, ff. 36 r-37 v.); realiza préstamos (de hecho, tenía un «libro de créditos» con su índice: AHPM, prot. 1695, 1695-VI-2, anexo final); compra y vende esclavas — que no esclavos- (AHPM prot. 1819, 1681-II-14, ff. 33 r-v.). Unas actividades que hicieron de él un hombre realmente rico: el inventario de sus propiedades ocupa cerca de 100 folios (AHPM, prot. 1826, 1695-II-8), y llega a poseer la mayor colección de pintura y objetos artísticos de la Murcia de su época. A este respecto véase AGÜERA ROs, José Carlos: Pintura y sociedad en el siglo XVII. Murcia, un centro del Barroco español, Murcia, 1994, p. 386.

${ }_{91}$ Con el cual forma una compañía, el año 1664, que es renovada tres años más tarde, en 1667. En esa segunda compañía Carnalla participa con 94.806 reales y su suegro con 342.025 reales: AHPM, prot. 791, 1667-X-21, f. 375 v.

92 Siendo testigos Francisco Ferro Verdín, D. Diego Páramo y Lara y Martín García Ponce. AMM, CC RR 1687, ff. 569 v-570 r.

${ }_{93} \mathrm{La}$ dote asciende a 6.000 ducados, a los que se añaden otros 1.172 ducados aportados por varios familiares «para más aumento de dote»: A.H.P.M., prot. 791, 1667-VII-15, ff. 275 r-281 v.

${ }_{94}$ Era hijo de Juan Bautista Ferro y Tomasina Carnalla: AMM, CC RR 1688, ff. 545 r-v.

95 Cuando en 1668 consigue la «naturaleza destos reinos» se reconoce que «a más de veintte años que reside en estos nuestros reinos de Castilla», estando avecindado y casado en Murcia. AMM, CC RR 1667-1671, 1668-VI-19, ff. 104 r-105 v. 
A partir de 1668 se ocupa de los negocios de la familia de su esposa, y se convierte, durante muchos años, en el principal comprador de seda en el Contraste. Continuando con la práctica iniciada por su suegro, es uno de los pocos mercaderes que invierte en la manufactura sedera local ${ }^{96}$, y que exporta seda y tejidos sederos a América ${ }^{97}$. Pero además de ello se dedica también al comercio de $\operatorname{sos}^{98}$ y al préstamo de dinero a corto plazo a huertanos, labradores, artesanos, viudas de regidores ${ }^{99}$, etc. y también al concejo de la ciudad: en 1672, por ejemplo, fue la persona que más dinero prestó al Pósito de Murcia, con 56.200 reales, el doble que el segundo mayor prestamista ${ }^{100}$.

Todo ello hará de él un hombre realmente rico: compra tierras en la huer$\mathrm{ta}^{101}$, llega a ser propietario de un molino harinero en la acequia Alfoz — que tenía arrendado ${ }^{102}$ — de casas — que también alquila ${ }^{103}$ —, juros ${ }^{104}$, etc.

Antonio Ferro Carnalla es el prototipo de mercader y hombre de negocios triunfador. Pero también es un modelo de movilidad social ascendente en la Murcia del último tercio del siglo XVII. En efecto, de ser sólo un extranjero que parte de cero, gracias a su familia y al comercio sedero llegará a acumular un patrimonio elevado y logrará acceder a altas dignidades sociales. Al igual que sus antecesores (Juan Bautista Verdín y Antonio Ferro Herguero) es reconocido como hidalgo ${ }^{105}$. Sin embargo, va a conseguir algo que no habían logrado los anteriores: participar como regidor en el gobierno de la localidad, cargo desde el cual llegará a ocupar puestos destacados al servicio de la corona.

Su carrera "política» es vertiginosa: el año 1668 es admitido como cofrade de la cofradía de Santiago, que sólo admitía a hidalgos limpios de sangre ${ }^{106}$; ese mismo año, y gracias al oficio comprado — y vinculado- por el obispo Verdín

${ }_{96}$ AMM, libro del Contraste de 1683, despachos.

97 AHPM, prot. 1818, 1673, ff. 125 r-v.

${ }_{98}$ En 1669 dos carreteros le llevaron 81 quintales desde Alhama hasta Albacete. AHPM, prot. 792, 1669-VII-31, ff. 213 r-v. En 1685 un carretero le debía dinero de un transporte de sosa realizado en 1683. AHPM, prot. 1821, 1685-III, f. 77 r.

99 AHPM, prot. 1819, 1681-IX-9, ff. 174 r-v.

100 Riquelme Pacheco, Alfonso: "Formas de crédito en el Pósito de Murcia en la segunda mitad del siglo XVII», en Contrastes, Revista de Historia Moderna (Murcia) 5-6 (1990), p. 48.

${ }_{101}$ AHPM, prot. 792, 1670-VII-12, ff. 254 r-258 v.

102 AHPM, prot. 792, 1669-XI-8, s. f.

103 AHPM, prot. 792, 1667-XII-27, ff. 454 r-v.

104 AHPM, prot. 792, 1668-III-13, ff. 89 r-93 v.

${ }^{105}$ En 1680 Antonio Ferro Carnalla inicia, junto a su «primo» y cuñado Juan Bautista Ferro Verdín, los trámites para ser declarados hidalgos (A.H.P.M., prot. 1819, 1680-I23-, ff. 10 r-v.). El proceso acabará siendo largo (no será hasta el 24 de enero de 1688 cuando el concejo acuerda aprobar su solicitud. AMM, CC RR 1687, ff. 417 r-722 r, 1688, ff. 1 r-618 v) y muy costoso, pues ha de realizarse casi en su integridad en Varazze. Como ejemplo de lo costoso de la misma, basta con prestar atención a la documentación producida: ésta, recogida en Cartas Reales, ocupa más de 300 folios en las pruebas de Juan Bautista y más de 600 en las de Antonio.

106 AMM, CC RR 1687, f. 628 v. 
Molina, tío de su esposa, es admitido como regidor en el concejo de Murcia ${ }^{107}$; en 1672 es nombrado familiar del Santo Oficio ${ }^{108}$; y en 1688 «alcalde de huerta por el estado noble»109. Por último, pero no menos importante, en $1683^{110}$ Antonio Ferro es nombrado «Consejero de Su Majestad en el Real de Hacienda»y «Gentilhombre de Su Majestad» ${ }^{111}$, distinciones y cargos que desempeñará hasta el momento de su muerte, en $1693^{112}$.

Como podemos observar, su carrera social y profesional es meteórica y sobrepasa con creces a la desarrollada por Juan Bautista Verdín (que sólo llega a ser aceptado como hidalgo y familiar del Santo Oficio) y Antonio Ferro Herguero, que únicamente cuenta con el reconocimiento de su hidalguía. Ahora bien, los tres individuos citados parten de una situación muy parecida (extranjeros llegados sin nada que gracias al apoyo de sus familias políticas logran medrar en los negocios y enriquecerse); sin embargo, sólo el tercer llegado logra ascender hasta cargos de responsabilidad política, y por tanto, hasta el grupo oligárquico local, con todo lo que ello representa también en la escala social.

Evidentemente, no se trata de una diferencia de dinero ni de relaciones sociales, pues todos ellos han disfrutado de una posición económica envidiable, y han estado muy bien relacionados con miembros destacados de la sociedad local (miembros del concejo, familiares del Santo Oficio, mercaderes, etc.), como hemos podido ver en páginas anteriores.

La diferencia principal estriba, a todas luces, en el desempeño del oficio de regidor, pues es éste, por encima de cualquier otro factor ${ }^{113}$, el que facilita su

107 Guillamón Álvarez, Francisco Javier y Ruiz IbÁÑEZ, José Javier: «Guía de regidores y jurados de Murcia: 1650-1800», en Cuadernos del Seminario «Floridablanca», 3. Sapere Aude. Murcia, Universidad de Murcia, 1996, p. 100.

${ }^{108}$ En él y su esposa «concurrían las zircunstancias y calidades de limpieza necesarias». AMM, AA CC 1672-IV-2; CC RR 1687, ff. 548 r-v.

109 Se le nombró el 24 de enero de 1688, ya en «Don Antonio concurren todas las calidades de limpieza y nobleza necesarias». AMM, CC RR 1688, f. 611 v. En el siglo XVI, para el desempeño del puesto de alcalde de huerta no se exigía la hidalguía, y fue ocupado por los más adinerados. CHACÓn JiméneZ, Francisco: Murcia en la centuria del quinientos, Murcia, 1979, p. 449.

${ }^{110}$ El 21 de octubre de 1683 dio «poder general» a Francisco Ferro Verdín para que administrara todos sus negocios ya que «estoy de partida para la Corte». AHPM, prot. 1820, 1683$\mathrm{X}-21$, s. f.

111 AHPM, prot. 1826, 1693-VII-6, ff. 129 r-v.

112 AHPM, prot. 1826, 1693-VII-6, f. 137 v.

113 Si bien es cierto que, en el caso del cargo desempeñado en el Consejo de Hacienda, también debió tener cierta importancia, por un lado, la influencia que en esos momentos tiene la comunidad genovesa en la corte (véanse, por ejemplo, RUIZ MARTín, Felipe: «La banca en España hasta 1782», en El Banco de España. Una historia económica, Madrid, 1970, pp. 104 y sgts; y CAPELla MARTíneZ, Miguel y Matilla Tascón, Antonio: Los Cinco Gremios Mayores de Madrid: estudio crítico bistórico, Madrid, 1957, p. 56); y por otra, las redes de relación que traza el propio Antonio Ferro. De hecho, en su nombramiento parece haber sido clave la relación que mantiene con el Tesorero del Consejo de Hacienda D. Juan de Morales, con el cual tenía negocios (muestra de ello es que el año 1681 le paga una letra por valor de 4.186 reales: AHPM, prot. 1819, 1681-XI-10, ff. 213 r-v.). 
llegada a la Corte y al Consejo de Hacienda ${ }^{114}$.

Ahora bien, como señalábamos al comienzo de este trabajo, son muchos los autores que han tratado de demostrar que el acceso al concejo, en la Castilla de los siglos XVI y XVII, era un asunto meramente crematístico: cualquiera que dispusiera del dinero suficiente para comprar a la corona un oficio de regidor podía acceder al órgano de poder municipal. Bajo esta premisa tanto Juan Bautista Verdín como Antonio Ferro Herguero podían haberlo hecho, pues no era exactamente dinero de lo que andaban escasos. ¿Debemos pensar que si no lo hicieron fue porque no estaban interesados en ello? Vistas algunas decisiones tomadas por éstos, en las cuales se puede observar su interés por asimilarse a las familias de poder local (adquisición de una capilla, ingreso en el Santo Oficio, búsqueda del reconocimiento de hidalguía), no parece que sea esa la razón. La causa puede encontrarse más próxima al rechazo (más o menos abierto) que estos ricos comerciantes foráneos producen en la muy conservadora elite local murciana, al menos en lo relativo al ingreso en el seno de dicho grupo social.

La primera prueba de ello la tenemos en el oficio que permite la entrada en el concejo de la ciudad a Antonio Ferro Carnalla: pese al mucho dinero que llega a acumular, la regiduría que desempeña no ha sido comprada por él, un mercader extranjero, sino por un obispo de la Santa Iglesia Católica que, pese a ser de origen genovés, es castellano por nacimiento.

La lectura de este hecho es, aparentemente, muy clara: la elite local murciana, al igual que en su momento hiciera la de Cartagena ${ }^{115}$, no parece muy bien dispuesta a abrir las puertas del concejo a un colectivo que, tanto por su potencial económico como por su origen y actividad profesional, puede resultar «peligroso ${ }^{116} »$. A este respecto, resulta muy significativa la identidad de la per-

${ }_{114}$ Murcia, como capital de Reino, tiene voto en Cortes, y son sus regidores quienes son enviados, en calidad de procuradores, a representar y defender los derechos de la ciudad y su Reino. Guillamón Álvarez, Francisco Javier et al:: La Corona y los representantes del Reino de Murcia (15901640): necesidad, negociación, beneficio, Murcia, 1995. Cuando las Cortes dejan de ser convocadas, es el propio concejo quien intermedia con la corona: véase MuÑOz RODRíGUEZ, Julio: "Consenso e imposición en la conservación de la monarquía: La práctica política en un territorio de la periferia castellana: el Reino de Murcia (1682-1700)», en Hispania (Madrid) 215 (2003), pp. 969-994.

115 Como señala F. Velasco, la entrada de Pedro Casanova (como ya vimos anteriormente, el primer mercader de origen extranjero que lo logra) en el concejo de Cartagena el año 1580 no es, en modo alguno, facilitado por el resto de capitulares, que intentan por medios diversos impedir que tome posesión de su cargo alegando, entre otras cosas, su origen genovés. Velasco HernáNDEZ, Francisco: "Comportamiento y estrategias...", ob. cit., pp. 233-234.

116 Entre otras razones, porque para un concejo que, desde finales del siglo XVI, está intentando adquirir estatuto de limpieza y nobleza, algo que no conseguirán hasta mediados del siglo XVIII (HernÁNDEZ FrANCO, Juan: «Limpieza y nobleza en las ciudades de Castilla: pretensiones y consecución del estatuto de limpieza de sangre por parte de Murcia (1560-1751)», en Revista de Historia Moderna, Universidad de Alicante, (Alicante) 17 (1998-1999), pp. 249-262), aceptar a un grupo social que abiertamente desempeña actividades innobles podía resultar, como mínimo, contraproducente. 
sona que vende la regiduría adquirida por el obispo Verdín Molina: la viuda de don Francisco Pérez de los Cobos, un individuo que, por origen e intereses, debe ser encuadrado más en la elite local de la villa de Jumilla (de donde era natural) que en la de la ciudad de Murcia117.

Tal vez en el último tercio del siglo XVI les hubiera sido más sencillo adquirir una regiduría tratando directamente con la corona (es el momento de creación y venta masiva de oficios concejiles ${ }^{118}$ ), pero la instalación de los Ferro y los Verdín en la ciudad de Murcia se produce cuando la enajenación de cargos públicos comienza a remitir (continuarán produciéndose, al menos, hasta comienzos de la década de 1660 , pero con una intensidad mucho menor ${ }^{119}$ ), y los nuevos oficios ofertados son captados casi en su totalidad por las familias de la elite local, en un intento por lograr, entre otras cosas, el cierre social de la institución ${ }^{120}$. Un cierre social que afecta también, lógicamente, al uso privado de los propios oficios: a tenor de lo observado, los propietarios de oficios no parecen estar muy dispuestos a vendérselos a cualquier recién llegado, por mucho dinero que estén dispuestos a pagar. Para una monarquía en apuros económicos es posible que no importe de dónde procede el dinero con el que se adquieren los oficios concejiles que ella misma oferta. Pero no parece ser lo mismo para el grupo de familias que tienen en el órgano de poder local su principal fuente de poder y distinción.

Ahora bien, las muestras de «rechazo» hacia los comerciantes genoveses por parte de las familias que componen la elite local murciana no se reducen a su remisión a venderles un oficio concejil, sino que van mucho más allá. Los aceptan como socios comerciales, como representantes de sus negocios o solicitudes, pero esas relaciones mercantiles o de representación no se transforman en vínculos de parentesco.

Buena prueba de ello la tenemos en las relaciones que cultiva, una vez instalado en Madrid, Antonio Ferro Carnalla (véase el cuadro 1). Por su posición privilegiada, próxima a los centros decisorios de la monarquía, son muchos los que solicitan sus favores. Así, contribuyó a que al regidor y familiar del Santo Oficio D. Macías Fontes se le concedieran dos hábitos de Orden de Santiago ${ }^{121}$

117 Véase, a este respecto, Molina PUCHE, Sebastián: «Aproximación al estudio de la hidalguía jumillana (1600-1650)», en CuTILlas DE MORA, José Miguel (ed.): Jumilla. Repertorio Heráldico, Murcia, 2003, pp. 254-271.

118 DOMínguez ORTIZ, Antonio: «La venta de cargos y oficios públicos en Castilla y sus consecuencias económicas y sociales», en Instituciones y sociedad en la España de los Austrias, Barcelona, 1985, pp. 146-183.

119 Véase, por ejemplo, MOLINA PUCHE, Sebastián: Como hombres poderosos. Las oligarquías locales del corregimiento de Chinchilla en el siglo XVII, Albacete, 2007.

120 Hernández Franco, Juan, y Peñafiel Ramón, Antonio: «Parentesco, linaje y mayorazgo en una ciudad mediterránea: Murcia (siglos XV-XVIII)», en Hispania (Madrid) 198 (1998), pp. 157-183.

${ }^{121}$ Macías Fontes dio poder a Antonio Ferro para que «...haga los depósitos que combengan de las cantidades y en las especies de moneda que le pareciere...». AHPM, prot. 1891, 1688-I-3, ff. 1 r-2 v. 
SOCIOS PERO NO PARIENTES. LOS LÍMITES DE LA PROMOCIÓN SOCIAL DE LOS COMERCIANTES...

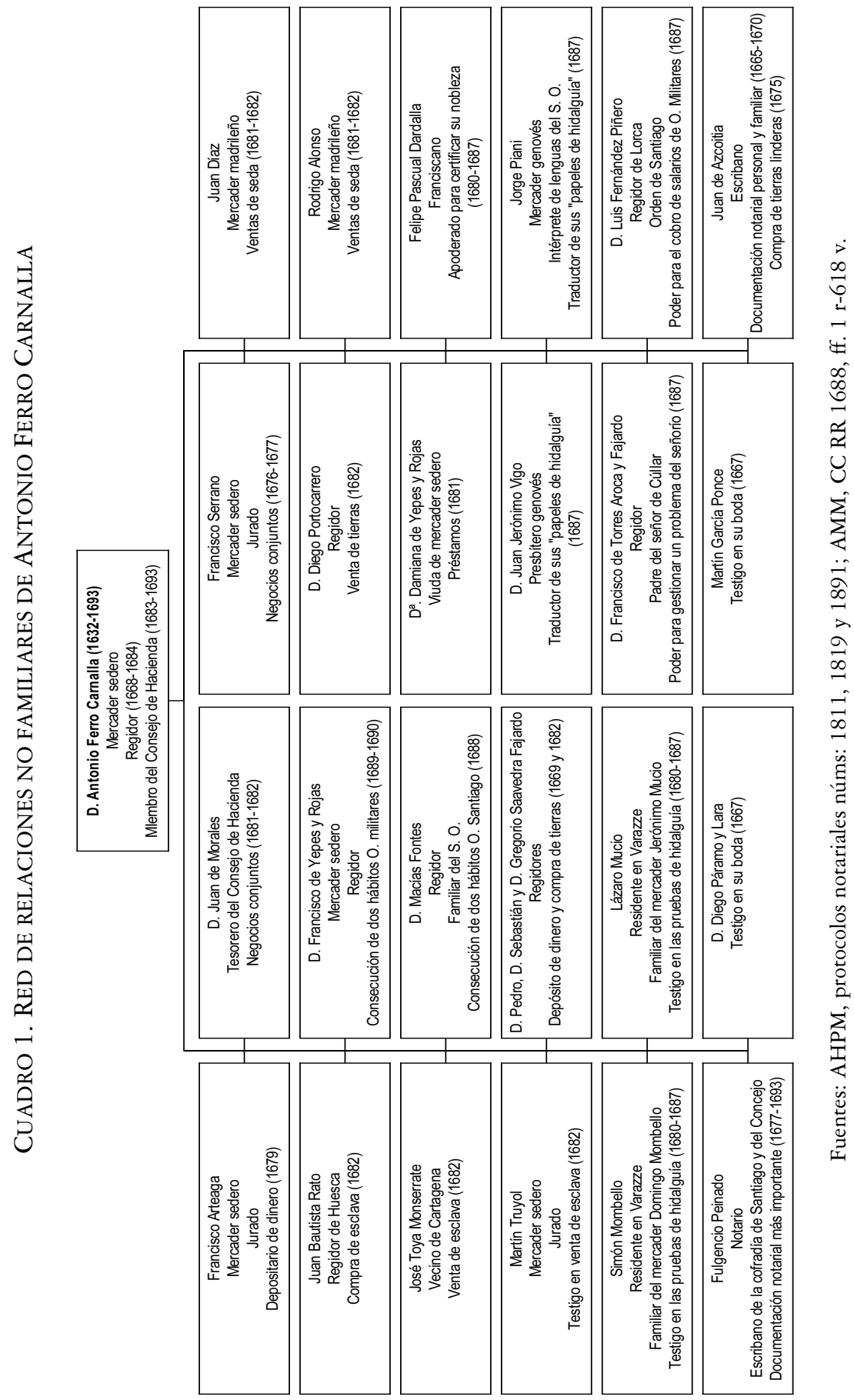

Hispania, 2007, vol. LXVII, no. 226, mayo-agosto, 455-486, ISSN: 0018-2141 
(algo que también hace para el mercader murciano Francisco de Yepes, a quien de igual manera se le conceden dos hábitos de Ordenes Militares ${ }^{122}$ ); ayudó a solucionar un problema legal al señor de Cúllar, hijo del regidor murciano Francisco de Torres Aroca ${ }^{123}$; logra que el regidor lorquino Luis Fernández Piñero cobrara los salarios que le correspondían por su trabajo en las pruebas de selección como miembro de una orden militar de un regidor de Murcia ${ }^{124}$; hizo varias gestiones en los Consejos favorables al concejo murciano ${ }^{125}$, etc.

Sin embargo, ni su posición en la Corte, ni su dinero, ni las gestiones realizadas a favor de muchos miembros destacados de la elite local murciana van a suponer el reconocimiento y aceptación de los Ferro por parte del grupo de poder local. El análisis de los matrimonios que van a llevar a cabo los cuñados y descendientes de Antonio Ferro Carnalla resulta muy significativo.

El matrimonio de doña Nicolasa Ferro Verdín tal vez no sea suficientemente representativo para el caso que nos ocupa, pues al igual que su hermana mayor, doña María, es casada con un pariente al que han «llamado» para ayudar en las empresas familiares: D. Juan Bautista Ferro Ferrutti, sobrino de Antonio Ferro Carnalla ${ }^{126}$. Es posible que, como en su día hiciera Juan Bautista Verdín, el objetivo buscado por Antonio Ferro Carnalla y sus cuñados con este matrimonio fuera traer de Génova un pariente que se encargara directamente de los negocios familiares, para así poder dedicarse ellos a labores más «honrosas». Sin embargo, también es posible que, al obrar de este modo, perdieran la posibilidad de haber entroncado con alguna familia del grupo elitista local, como ocurriera en su día con doña Josefa Verdín Molina. De familia noble, heredera, como ya señalamos, de bienes por valor de 93.000 reales — una pequeña fortuna-, hermana de un canónigo de la Iglesia catedral y de un regidor perpetuo de la ciudad de Murcia, sobrina de un obispo, cuñada de un miembro del Consejo Real de Hacienda..., no cabe duda que doña Nicolasa habría sido considerada como un muy buen partido.

Con todo, el matrimonio de sus hermanos y sobrinos sí que resulta revelador.

En efecto, en el año 1681 se casa su hermano Juan Bautista Ferro Verdín. A todas luces, cumplía con todos los requisitos necesarios para haber sido bien recibido en el mercado matrimonial de la «buena sociedad» murciana. Rico, noble (recordemos que en esos momentos ha iniciado, junto a su cuñado, las pruebas de nobleza), ese mismo año comienza a ejercer un oficio de regidor (el mismo que ha desempeñado su cuñado ${ }^{127}$ ), y lo que es más importante: acaba

122 AHPM, prot. 3660, 1702-VII-21, ff. 328 v-329 v.

123 AHPM, prot. 1816, 1687-V-30, ff. $334 \mathrm{r}-335 \mathrm{v}$.

124 AHPM, prot. 1816, 1687-XII-16, ff. 399 r-v.

125 AHPM, prot. 1822, 1687-IV-29, ff. 103 r-104 v.; prot. 1824, 1691-VII-14, ff. 100 r-101 v.

${ }^{126}$ Hijo del capitán Onofre Ferro Carnalla y de María Magdalena Ferrutti: AMM, AA CC 1703-VI-2, ff. 67 r.

127 AMM, CC RR 1678-1682, 1681-III-1, ff. 101 v-104 r. "Don Juan Ferro Verdín, reximiento, en lugar de don Baltasar Fontes». 
de convertirse en el segundo poseedor del vínculo Verdín por fallecimiento de su tía Josefa Verdín Molina. A todo lo cual hay que añadir que, desde el año 1688, es nombrado consejero del Real de Hacienda ${ }^{128}$.

No obstante, acaba casando en la villa de Albacete, por poderes ${ }^{129}$, con doña Constanza Salvador y Almodóvar, hija del oidor de la Audiencia de Valencia y caballero de la orden de Montesa don José Gaspar Ruiz Salvador. Perteneciente a una noble familia y heredera de varios vínculos (el fundado por su bisabuela Francisca Sandoval y el fundado por José Verástegui y Salvador ${ }^{130}$ ), Constanza Salvador no dejaba de ser un buen partido, pero no servía de gran ayuda para acceder al grupo dirigente local de la ciudad de Murcia.

Capital simbólico, capital económico y relacional, es mucho lo que puede ofrecer don Juan Bautista. Sin embargo, porta dos grandes máculas que no pasan desapercibidas a los miembros de la elite local: continúa dedicándose al comercio ${ }^{131}$ y es de origen extranjero.

Caso más llamativo es, sin lugar a dudas, el de su hermano menor Antonio Ferro Verdín, al cual adornaban méritos semejantes (es regidor desde 1693 hasta 1726), pero fallece, a los sesenta años de edad, soltero ${ }^{132}$. ¿Decisión personal, estrategia familiar o ausencia de una propuesta de matrimonio que cumpliera sus expectativas sociales? En estos casos, suelen ser más las dudas que las certezas.

No va a correr mejor suerte la generación siguiente, pese a que, por razones biológicas $^{133}$ —Nicolasa y Juan Bautista Ferro Ferruti no van a dejar descendencia, y ninguno de los hijos nacidos del matrimonio de Don Juan Bautista Ferro Verdín y doña Constanza Salvador van a llegar a edad adulta-, todo el patrimonio familiar — vínculos y mayorazgos incluidos_ va a quedar en manos del único hijo superviviente de Antonio Ferro Carnalla y doña María Ferro Verdín: D. Antonio Ferro Ferro.

128 AHPM, prot. 1826, 1696-XII-14, ff. 148 r-149 r. Algo en lo que mucho tuvo que ver su primo y cuñado, en esos momentos todavía miembro de dicho consejo. Si bien es cierto que duraría poco en el cargo: al igual que su cuñado, fallece en el año 1693.

129 Tuvo que dar poderes a su hermano Francisco, «...tengo tratado y ajustado de contraer matrimonio..., porque las ocupaciones en que me allo de asistencias precisas en esta ciudad de Murcia, no puedo yr personalmente a la celebrazión del dicho matrimonio...». A.H.P.M., prot. 1819, 1680-XII-28, ff. 266 r-v.

130 «Testamento de Juan Ferro Verdín», AHPM, prot. 1826, 1693-IV-7, ff. 1 r.-4 r., anexo; «Testamento de Constanza Almodóvar», AHPM, prot. 1826, 1687-VII-10, ff. 68 r-75 v., anexo.

131 Aunque una de sus principales dedicaciones va a ser la nada innoble administración de las cada vez más extensas propiedades familiares y de los bienes y rentas de la Reverenda Cámara Episcopal (AHPM, prot. 1821, 1685-II-6, ff. 28 r-29 v), también comercia con seda, sosa (AHPM, prot. 1821, 1685-II-26, f. 64 r), hojas de morera (AHPM, prot. 1819, 1680-IV-9, ff. 40 r-v), mulas (AHPM, prot. 1253, 1676-VIII-21, ff. 185 r-v), y presta dinero (AHPM, prot. 1820, 1683-XI-6, s. f.).

132 CANDel Crespo, Francisco: Familias..., ob. cit., p. 19.

133 Como ha demostrado Mauro Hernández en el caso de la oligarquía concejil madrileña. Véase HernándeZ, Mauro: A la sombra de la Corona, Madrid, Siglo XXI, 1995. 
Nacido en 1675, quedó en una situación económica excepcionalmente favorable (prueba de ello es que, en concepto de arras, aporta a su matrimonio bienes valorados en 10.000 ducados). No obstante, casará, en 1707, con Nicolasa Buendía Barnuevo ${ }^{134}$, hija de una noble familia (su padre, Pedro Buendía, es caballero de Santiago) que, una vez más, es de origen foráneo: la rama Buendía a la que pertenece se encuentra avecindada en la ciudad de Granada. Es cierto que, por parte materna, procede de una familia murciana, pero no especialmente honorable: su abuelo, don Alonso de Barnuevo, había sido también mercader sedero y receptor del Santo Oficio ${ }^{135}$.

Este matrimonio, al igual que el de don Juan Bautista Verdín, ejemplifica hasta qué punto resulta dificultoso a los Ferro ser aceptados, vía matrimonial, por la elite local murciana. Don Antonio Ferro Ferro no puede ser acusado de dedicarse a una actividad comercial que desprestigiaba —algo que no hace, al menos abierta y directamente-, pues su principal dedicación es administrar sus rentas y propiedades, como cualquier noble terrateniente ${ }^{136}$. Sin embargo, la memoria genealógica de la comunidad parece ser realmente larga: don Antonio Ferro Ferro carga con la lacra de ser el hijo de un mercader extranjero, algo que, de cara a la muy conservadora elite murciana - fuertemente marcada por los valores nobiliarios y veterocristianos ${ }^{137}$ — no puede ser eliminado con dinero.

Pero también hay que entender la postura de las familias que conforman la elite local murciana. En esos momentos — si bien es cierto que se trata de un proceso iniciado, en la mayor parte de los casos, a comienzos del siglo XVII, y que se acelera enormemente durante el reinado de Carlos II- están tan necesitadas de dinero como de honores, pues son muchas las que se encuentran en pleno proceso de promoción social. De hecho, el sector más selecto e importante de familias del grupo dirigente local - aquellas con las cuales, por lógica y dado el enorme potencial económico de los Ferro, debían establecer los lazos de parentesco-, están intentando ascender a la nobleza titulada ${ }^{138}$, con lo cual no

${ }^{134}$ CAndel Crespo, Francisco: Familias..., ob. cit., pp. 76-77.

135 Miralles Martínez, Pedro: La sociedad de la seda..., ob. cit., p. 243.

136 Unas propiedades que contribuye a aumentar comprando, por ejemplo, tierras dedicadas al cultivo de la morera: AHPM, prot. 3652, 1700-XII-19, ff. 288 r-289 v.

137 Hernández Franco, Juan y PeÑafiel Ramón, Antonio: «Parentesco, linaje y mayorazgo...», ob. cit., pp.vv.; véase también HernáNDEZ FrANCO, Juan: "Cultura de élites y estratificación social en la España Moderna: aproximación metodológica a través de los estatutos e informaciones de limpieza de sangre», en HERNÁNDEZ FrANCO, Juan (coord.): Familia y poder: sistemas de reproducción social en España (siglos XVI-XVIII), Murcia, 1995, pp. 81-99.

${ }_{138}$ Una buena síntesis de la evolución secular de dicho grupo social en PÉREZ PICAZO, María Teresa: «De regidor a cacique: las oligarquías municipales murcianas en el siglo XIX», en SaAvedra, Pegerto y Villares, Ramón (eds.): Señores y campesinos en la Península Ibérica, siglos XVIII-XIX, Barcelona, 1991, vol. I, pp. 16-37. Sobre la concesión de títulos nobiliarios a esas mismas familias, ALARCón PEDrEÑo, Antonio A: «Estrategias familiares en el proceso de transición entre señorío jurisdiccional y nobleza titulada en la Murcia del Setecientos», en CASEY, James y Hernández Franco, Juan (eds.): Familia, parentesco y linaje, Murcia, 1997, pp. 293-300. 
pueden darse el lujo de enlazar matrimonialmente con familias que puedan deslucir los títulos recientemente adquiridos o suponer una traba a la consecución de los mismos.

De ahí que los Ferro, por mucho capital económico y relacional que hayan podido acumular, acaben viéndose abocados a recurrir al matrimonio con prestigiosas familias nobles foráneas, como los Salvador o los Buendía. Unas familias que, al parecer, no se muestran tan remisas con sus orígenes porque, entre otras razones, tampoco pueden alardear de nobles ancestros - caso, como acabamos de ver, de los Barnuevo-, pero al mismo tiempo ofrecen la ventaja de añadir cuarteles al blasón familiar. No importa que esos cuarteles sean, al igual que el que ellos ofrecen, relativamente recientes, lo interesante es que suman, y todos en conjunto pueden ocultar, o al menos maquillar, máculas de origen para las generaciones siguientes.

La estrategia de acumulación de cuarteles, abandono y ocultación de actividades deshonrosas y adopción del more nobilium, al final, parece funcionar: don José Ferro Buendía, hijo primogénito de don Antonio Ferro y doña Nicolasa Buendía, será finalmente aceptado por una familia de la elite local, al casar con doña María Teresa Melgarejo Puxmarín, perteneciente a una antigua familia noble que, aunque originaria de Caravaca ${ }^{139}$, se encuentra firmemente establecida en la cúspide de la sociedad local murciana.

\section{Conclusiones}

Es un hecho de sobra conocido que, a lo largo del Antiguo Régimen, el dinero fue cobrando paulatinamente importancia como elemento dinamizador de los procesos de promoción social. En el caso español, en la historiografía modernista no se ha hecho más que aportar ejemplos en los cuales se intenta constatar este extremo. No obstante, de algunos estudios recientes se puede colegir que se ha llegado a un estadio en el cual el factor honorífico parece haber quedado en un plano muy secundario, casi residual. No cabe duda que la posesión de riqueza facilitó la obtención de honras y oficios prestigiosos a numerosos individuos - $\mathrm{y}$ familias - que, por nacimiento, difícilmente podrían haber optado a ellas en una sociedad férreamente estamentalizada. Ahora bien, por lo que hemos podido ver en el caso analizado, no se podían obtener todo tipo de honras por medio del peculio, ya que se tenía en cuenta la procedencia del dinero, y como es bien sabido, la ocupación mercantil «maculaba» (y por tanto, invalidaba) ese dinero. Y lo que tal vez sea más importante, los recién llegados no eran aceptados fácilmente por los que debían ser «sus iguales»: en el caso de los Ferro Verdín, tras el paso de cinco generaciones, han tenido que abandonar

139 LEMEUNIER, Guy: «Las cuentas de Melgarejo: un patrimonio murciano a mediados del siglo XVII», en Economía, sociedad y política en Murcia y Albacete (s. XVI-XVIII), Murcia, 1990, pp. 177-214. 
la actividad comercial —al menos, como ya hemos señalado, el desempeño directo de la misma - origen de su fortuna y, al mismo tiempo, se han visto en la obligación de adoptar, una por una, las señas de identidad de la elite de poder para ser reconocidos como miembros de pleno derecho, y no como unos simples advenedizos imitadores de una pautas de conducta que no les corresponden por cuna.

Eso sí, parece que la aceptación en el grupo elitista murciano, aunque tardía, viene acompañada de un "premio» suficientemente importante como para considerar que todo los esfuerzos han valido la pena, pues en el año 1790 José Ferro Melgarejo es nombrado conde de la Real Piedad — casi doscientos años después de que sus antepasados arribaran a las costas murcianas procedentes de Varazze- Pero resulta muy significativo que, pese a la mucha capacidad económica de la familia, y la buena posición que algunos de sus miembros llegan a tener en la estructura político-administrativa de la corona, dicho "premio» no llega hasta mucho después de haber abandonado la actividad comercial y, sobre todo, tras haber sido admitidos, tras emparentar con una de las más antiguas y blasonadas familias murcianas (los Melgarejo Puxmarín), en el grupo dominante local.

En definitiva, el ejemplo de la familia Ferro Verdín puede servirnos para ilustrar la afirmación que realizábamos al comienzo de este trabajo, es decir, que el dinero, en la Castilla de los siglos XVI al XVIII, era un elemento imprescindible, pero no suficiente, para promocionar socialmente. Podía servir para adquirir honores y distinciones, pero en modo alguno podía comprar conciencias y conformidades. Además del dinero, las relaciones sociales también son necesarias en la lucha individual y familiar por el honor. Éste, aunque mermado, seguía teniendo un peso determinante en la estratificación social castellana, hasta el punto de que familias como las que nos ha ocupado acaben prefiriendo abandonar actividades económicas altamente rentables con el fin de poder acrecentar su prestigio. Un prestigio que, evidentemente, continuará teniendo una fortísima carga estamental. Los actores sociales actúan para prosperar y garantizar su posición en la sociedad, y ésta es más importante que la posesión de bienes materiales. 


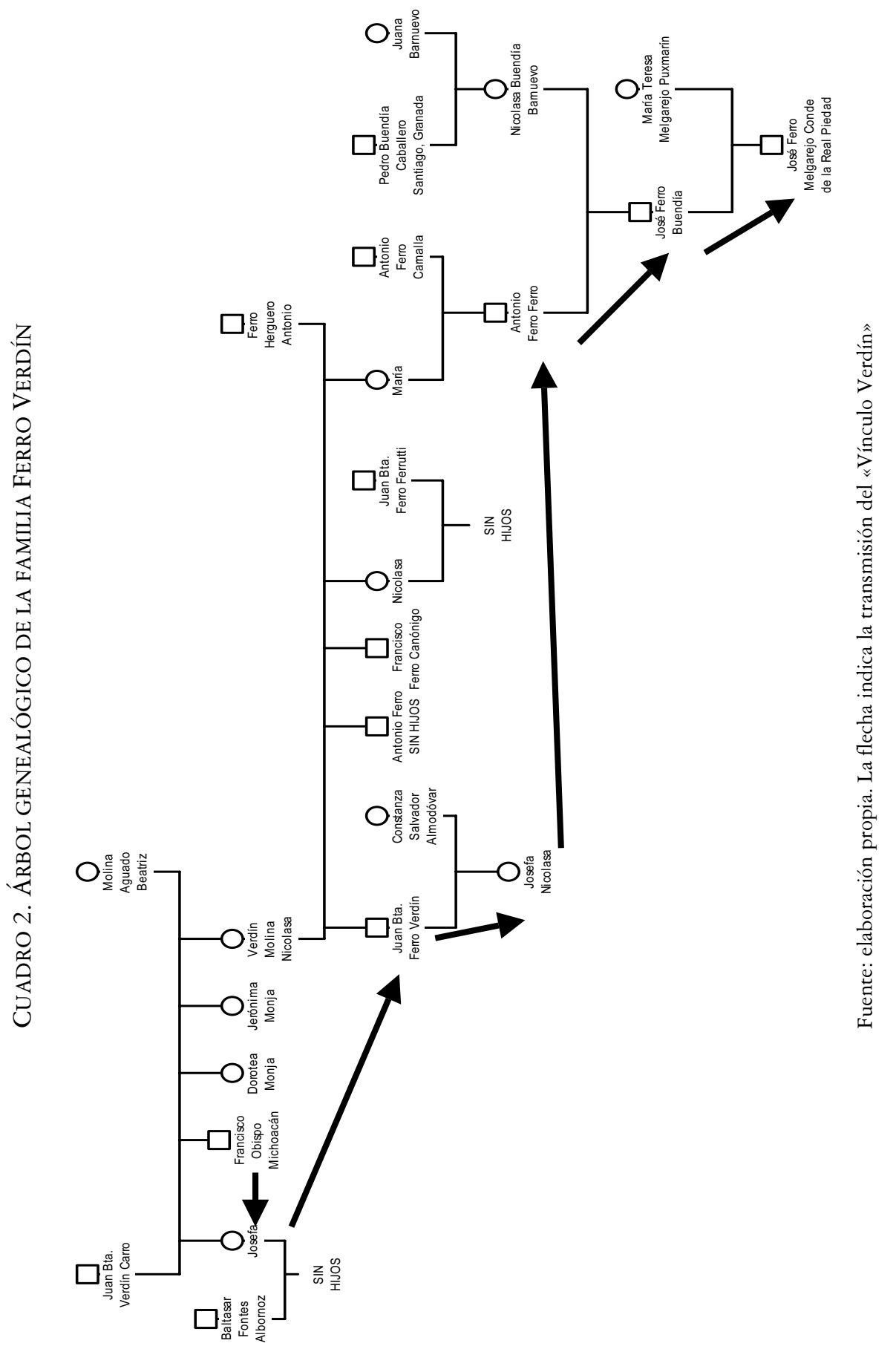

Hispania, 2007, vol. LXVII, nº. 226, mayo-agosto, 455-486, ISSN: 0018-2141 